\title{
On the range of future Sahel precipitation projections and the selection of a sub- sample of CMIP5 models for impact studies
}

Article

Accepted Version

Monerie, P.-A. ORCID: https://orcid.org/0000-0002-5304-9559, Sanchez-Gomez, E. and Boé, J. (2017) On the range of future Sahel precipitation projections and the selection of a subsample of CMIP5 models for impact studies. Climate Dynamics, 48 (7-8). pp. 2751-2770. ISSN 0930-7575 doi: https://doi.org/10.1007/s00382-016-3236-y Available at https://centaur.reading.ac.uk/100408/

It is advisable to refer to the publisher's version if you intend to cite from the work. See Guidance on citing.

To link to this article DOI: http://dx.doi.org/10.1007/s00382-016-3236-y

Publisher: Springer

All outputs in CentAUR are protected by Intellectual Property Rights law, including copyright law. Copyright and IPR is retained by the creators or other copyright holders. Terms and conditions for use of this material are defined in the End User Agreement. 


\section{www.reading.ac.uk/centaur}

\section{CentAUR}

Central Archive at the University of Reading

Reading's research outputs online 
1 On the range of future Sahel precipitation projections and 2 the selection of a sub-sample of CMIP5 models for impact

3 Studies

4 Paul-Arthur Monerie ${ }^{1}$; Emilia Sanchez-Gomez ${ }^{2}$, Julien Boé2.

$5 \quad{ }^{1}$ CECI UMR 5318 - CNRS/CERFACS, Toulouse, France; previously at Centre de Recherches en

6 Climatologie, UMR6282, CNRS/University of Burgundy, Dijon, France.

$7 \quad{ }^{2}$ CECI UMR 5318 - CNRS/CERFACS, Toulouse, France 


\section{Abstract}

13 The future evolution of the West African Monsoon is studied by analyzing 32 CMIP5 models under the rcp8.5

14 emission scenario. A hierarchical clustering method based on the simulated pattern of precipitation changes is used to

15 classify the models. Four groups, which do not agree on the simple sign of future Sahel precipitation change, are

16 obtained. We find that the inter-group differences are mainly associated with the large spread in (i) temperature increase

17 over the Sahara and North Atlantic and in (ii) the strengthening of low and mid-level winds. A wetter Sahel is

18 associated with a strong increase in temperature over the Sahara $\left(>6^{\circ} \mathrm{C}\right)$, a northward shift of the monsoon system and a

19 weakening of the African Easterly jet. A dryer Sahel is associated with subsidence anomalies, a strengthening of the

$20600 \mathrm{hPa}$ wind speed, and a weaker warming over the Northern Hemisphere. Moreover, the western (central) Sahel is

21 projected to become dryer (wetter) during the first months (last months) of the rainy season in a majority of models. We

22 propose several methods to select a sub-sample of models that captures both the ensemble mean pattern and/or the

23 spread of precipitation changes from the full ensemble. This methodology is useful in all the situations for which it is

24 not possible to deal with a large ensemble of models, and in particular most impact studies. We show that no

25 relationship exists between the climatological mean biases in precipitation and temperature and the future changes in

26 the monsoon intensity. This indicates that the mean bias is therefore not a reliable metric for the model selection. For

27 this reason, we propose several methodologies, based on the projected precipitation changes: The "diversity" method,

28 which consists in the selection of one model from each group is the most appropriate to capture the spread in

29 precipitation change. The "pattern selection" method, which consists in the selection of models in a single group allows

30 to select models for the study of a specific pattern of precipitation change, for example the one that is the most

31 representative of the full ensemble. 


\section{Introduction}

Observational studies show that the 1970s and 1980s were abnormally dry in the Sahel (L'Hote et al., 2002;

Sahel precipitation is inextricably linked to the West Africa Monsoon (WAM). Studies based on CMIP3/5 projections show that the WAM response to global warming is highly model-dependent. As a consequence, model based projections of WAM and Sahel climate are highly uncertain. This is particularly problematic for the assessment of socio-economic impacts, since in order to capture correctly the uncertainties (model formulation, internal variability, emission scenario), a large ensemble of models is necessary, as well as different realizations and scenario emissions should be considered. The CMIP5 multi-model ensemble consists in more than 40 climate models, with generally several realizations (or members), and for 4 different Representative Concentration Pathways (RCPs). It is virtually impossible for most groups working on dynamical downscaling and/or impacts, given limitations in computing resources and/or data storage capacity, to deal with such a large ensemble. Sub-sampling is necessary and given the major inter-model differences regarding the future evolution of Sahel precipitation, it is particularly complex in this context.

The need for an adequate sub-ensemble of models is becoming more and more frequent, since in the recent years an increasing number of multi-disciplinary impact studies have emerged: they are based on crop models (Sultan et al., 2014); on hydrological models ( $\mathrm{Li}$ et al., 2015); on land-cover and land use models (Xue et al., 2012); on malaria (Caminade et al., 2014) and meningitis modeling (Abdussalam et al., 2014); among others. The African countries will be indeed affected by global warming in many areas and will face important adaptation challenges. In this study, we propose different approaches to define an optimal sub-sample of models (composed by a small number of models, 
which is able to provide a mean pattern and inter-model spread of precipitation change close to them of the CMIP5 ensemble), based on the models response in Sahel precipitation under global warming.

The first step of the study is focused on the analysis of the diversity of CMIP5 future projections for Sahel precipitation. Precipitation is projected to increase (decrease) over the central (western) Sahel in both CMIP3 and CMIP5 multi-model ensembles (Fontaine et al., 2011b; Monerie et al., 2012; 2013; James and Washington, 2013; Biasutti, 2013; James et al., 2015). In a recent study, Park et al. (2015) suggest that the discrepancies in future Sahel projections can be explained by differences between Northern and Southern Hemisphere surface warming. Here, we revisit this question with an original statistical approach, based on hierarchical clustering applied to the projected patterns of Sahel precipitation change.

Sahel precipitation change uncertainty is caused by multiple competing physical mechanisms that impact the interannual-to-multidecadal variability of Sahel precipitation. Additionally, the Tropical Atlantic is a region of large model uncertainties: state-of-the-art climate models exhibit large systematic errors (Richter and Xie, 2008; Richter et al., 2012) and large uncertainties exist in the relative roles of internal and external factors in shaping climate change. The review of Druyan (2011) highlights that the studies based on CMIP3 projections often show opposite results, ranging from a significant increase to a significant decrease in Sahel precipitation at the end of the $21^{\text {st }}$ century. Different physical mechanisms have been proposed to explain the opposite responses found in coupled models. On the one hand, a wetter Sahel is associated with increased land-sea temperature contrast (Haarsma et al., 2005) between the Gulf of Guinea and the Sahara, and with a strengthening of the Tropical North Atlantic/Tropical South Atlantic temperature gradient (Hoerling et al., 2006; Park et al., 2015). On the other hand, the Tropical Ocean warming may induce an increase in moist static energy at upper levels, affecting then the vertical stability of the atmosphere, leading to a drying over the Sahel, in a way analogous to the impacts of El Niño Southern Oscillation on the global tropical atmosphere (Giannini et al., 2010). Our objective is to better understand the physical mechanisms responsible for the major inter-model spread in Sahel precipitation change. We also investigate whether the future model responses are linked to present-day climatological biases in Sahel precipitation. This question is of interest, since some models subsampling approaches are based on the models ability to simulate the mean historical climate (as in Buontempo et al., 2015), making the implicit hypothesis that models with smaller biases provide more reliable future projections. 
92 precipitation changes. The main objective is to find a small subset of models that both reproduces the ensemble mean 93 and inter-model spread of the full CMIP5 ensemble.

94

95 The main scientific questions addressed in this study can be summarized as follows:

96 1. Which are the main responses in future Sahel precipitation and the associated physical mechanism in CMIP5 models 97 at the monthly time-scale?

98 2. Is the large inter-model spread in future precipitation changes linked to present-day climate characteristics?

99 3. Is it possible to define a subset of models, representative of the full ensemble in terms of ensemble mean and spread?

The paper is organized as follows: In section 2 we describe the methodology and the data used. The mean 102 changes in Sahel rainfall are analyzed in section 3. Section 4 focuses on models biases and proposes different methods 103 for model selection. Finally we conclude in section 5 with a summary and a discussion of our results.

104 
2. Data and Methodology

107

108

2.1 Data

Observed precipitation for the 1979-2010 period from the GPCP v2.2 data set is used with a $2.5^{\circ} \times 2.5^{\circ}$ horizontal grid resolution. GPCP is a merged analysis that incorporates precipitation estimates from microwave data, infrared data, and surface rain gauge observations (Adler et al., 2003). Surface temperature, wind and sea level pressure for the period 1979-1999 come from the ERA-Interim (ERAI) reanalysis (Dee et al., 2011). Compared to ERA-40 (Uppala et al., 2005), ERAI provides an improved representation of the hydrological cycle over the tropics (Uppala et al., 2008), a more realistic stratospheric circulation and better temporal consistency of the reanalysis fields (Dee et al., 2011).

Two sets of numerical experiments from the CMIP5 archive (Taylor et al., 2012) are analyzed: the historical ensemble (hereinafter HIST, forced by both historical natural and anthropogenic forcings); and the RCP8.5 ensemble (noted RCP85, based on the most extreme scenario whose radiative forcing reaches $8.5 \mathrm{~W} / \mathrm{m}^{2}$ in 2100 ; see Meinshausen et al., 2011). We selected the models for which the necessary variables to this study are available for both HIST and RCP85, which leads to an ensemble of 32 models (see the figure 1 for the model names).

In this work, mean model biases are estimated from the JAS (July-August-September) differences between HIST and GPCP or ERAI on the 1979-1999 period. The models response to global warming is defined as the difference between RCP85 in the 2060-2099 period and HIST on the 1960-1999 period. Models outputs, GPCP precipitation and ERAI variables have been interpolated on the same $2.5^{\circ}$ latitude by $2.5^{\circ}$ longitude grid to facilitate the analysis. One member is considered for each of the 32 models for both the HIST and RCP85 experiments. Throughout this work, the multi-model response is considered as robust if at least $80 \%$ of the models agree on the sign of the change.

\subsection{Model classification}

Future projected changes in Sahel precipitation from the 32 CMIP5 models are classified with a hierarchical clustering algorithm (Jain et al., 1999). The spatial pattern to be classified is the JAS RCP85 - HIST differences in precipitation over a Sahelian box defined as $20^{\circ} \mathrm{West}-20^{\circ}$ East and $10^{\circ}$ North $-20^{\circ}$ North (including both the Western and Central box in Fig. 2a). The spatial correlation matrix is then computed (32 x 32 size). The hierarchical clustering is performed following the ward minimum variance method (Ward, 1963), based on the spatial correlation amongst the 
models. The position at which two models are connected on the tree characterizes their disagreement. Four groups of models are empirically defined based on the classification shown in Figure 1, noted GR1, GR2, GR3 and GR4 hereinafter. The semi-empirical choice of the number of clusters rests on a compromise, aiming to avoid clusters of very small size (whose properties could be strongly impacted by an outlier), and to have a sufficient number of groups to capture correctly the discrepancies in Sahel precipitation changes.

Precipitation changes are expected to be consistent within each cluster, which is not the case for the full ensemble. The goal of this classification is to facilitate the understanding of the diversity of projected precipitation changes in the Sahel by CMIP5 models.

Two outliers are identified by the classification: two GFDL models (gfdl_esm2g and gfdl_esm2m), whose responses are largely different from the other models, and finally they are included in any group. As in Pennell and Reichler (2011), Masson and Knutti (2011) and Knutti et al. (2013), models from the same institution generally belong to the same cluster (i.e. HADGEM, GFDL, IPSL, CMCC, MIROC, GISS, ACCESS and MPI). These similarities are due to the fact that models from the same center sometimes only differ in resolution (ipsl_cm5a_mr and ipsl_cm5a_lr for example), and generally share large portions of numerical code or even identical component (e.g. ocean, atmosphere or land models) (Masson and Knutti, 2011).

In the following section, changes in precipitation, temperature, pressure and winds over West Africa for the four groups of models defined above are studied. 


\section{Characterization of projected changes in the Sahel}

\section{1. Water budget}

Future changes in JAS Sahel precipitation (P), evaporation (E) and P-E budget for the four groups of models identified by hierarchical clustering are depicted in Figure 2. The intra-cluster mean is computed and the result is considered as robust when at least $80 \%$ of models within the cluster agree on the sign of the change. GR1 exhibits a large increase in rainfall (> $2 \mathrm{~mm} /$ day) over the entire northern Sahel (Fig. 2a). Over the adjacent ocean, evaporation slightly increases (Fig. 2e) yielding to a positive P-E budget, indicating an enhancement of moisture flux convergence (divergence), over the Sahel (Gulf of Guinea). This pattern has been widely documented in the past, and is associated with a strengthening of the land-ocean temperature contrast (Maynard et al., 2002; Haarsma et al., 2005; Skinner et al., 2012), and inhomogeneous ocean temperature changes within the Tropical Atlantic basin (i.e. the Tropical North Atlantic warms more than the Tropical South Atlantic, as reported in Hoerling et al., 2006). GR2 simulates a slight increase in precipitation over the central Sahel, and a decrease in precipitation over the Senegal (Fig. 2b). An important increase in precipitation along the maritime Inter-Tropical Convergence Zone (ITCZ) is also robust. GR2 also exhibits a strong increase in E over the adjacent ocean and west of central Africa (Fig. 2f). The resulting P-E budget is strongly negative over the Gulf of Guinea, and no robust changes are observed over the Sahel (Fig. 2j). Therefore, in GR2 the change in precipitation over the Sahel is not associated with a change in moisture flux convergence, suggesting that it might be linked to local changes in moisture recycling (the evaporation is moisture-limited rather than energy-limited in the semi-arid Sahel). GR3, which is the most populated cluster, shows a robust increase in P over the north-central Sahel and a decrease over its western part (Fig. 2c). The patterns for E and P changes are similar over the continent, but differ over the ocean, where E increases more strongly (Fig. 2c and Fig. 2g). The P-E budget increases (decreases) over the central (west) Sahel (Fig. 2k), indicating an increase (a decrease) in moisture flux convergence. These changes in the water budget have been already documented by Fontaine et al. (2011b), Monerie et al. (2012; 2013), James and Washington (2013), Biasutti (2013) and James et al. (2015): GR3 is the dominating response in the CMIP5 fullensemble. The response for GR4 consists in a slight decrease in P over both the continent and the ocean (Fig. 2d). E decreases over the central Sahel but increases over the Gulf of Guinea area (Fig.2 h). No robust changes are found for the P-E budget over the continent, whereas a robust decrease in P-E occurs over the Gulf of Guinea (Fig. 21).

In summary, four main types of projected precipitation changes over the Sahel can be extracted from the CMIP5 full-ensemble: a strong increase in precipitation (>2 mm/day, GR1), a zonal dipole with an increase (a decrease) 
in precipitation over the western (central) part (GR2 and GR3, but with a small increase in precipitation over the central Sahel in GR2); and finally a decrease in P over the entire domain (GR4). These patterns are consistent with the large spread in the WAM changes simulated by CMIP3 models (Druyan, 2011), and illustrate the strong uncertainties in Sahel precipitation projections. In the next section we analyze the atmospheric dynamics associated with the P, E and PE changes described above.

\subsection{Atmospheric circulation and temperature}

Figures 3a-d show the projected changes in $2 \mathrm{~m}$ temperature (T2m hereinafter, shading), sea level pressure (SLP, contours) and wind at $950 \mathrm{hPa}$ (arrows) for the four groups of models. From Figure 3, it is evident that the magnitude of $\mathrm{T} 2 \mathrm{~m}$ changes is different among the groups. However, the spatial patterns of warming present large similarities, with stronger increases in temperature over the continent than over the ocean, which act to increase the land-sea temperature gradients (Fig. 3a-d). The associated dynamics show a marked decrease in SLP over northern Africa, together with a strengthening of the south-westerlies (as shown in Haarsma et al., 2005) for the 4 groups of models. Over the Sahara, the SLP decreases, indicating a deeper heat low, which favors the strengthening of low-level winds. The main inter-group differences concern the intensity of the warming and of the wind strengthening.

At global-scale, surface temperature increases more in the northern Hemisphere than in the Southern Hemisphere for the four groups, which could act to enhance precipitation over the Sahel (Park et al. 2015). This interhemispheric differential warming in JAS is considered here only over the Atlantic Ocean, and computed as the RCP85HIST difference of SSTs averaged between $75^{\circ} \mathrm{W}$ and $10^{\circ} \mathrm{E}$, minus the global tropical SST change (the global tropical domain is $180^{\circ} \mathrm{W}-180^{\circ} \mathrm{E} ; 30^{\circ} \mathrm{S}-30^{\circ} \mathrm{N}$ ). Results for the four groups of models are shown in Figure 4. The major differences amongst the groups are located north of $40^{\circ} \mathrm{N}$. GR1 and GR3 exhibit a stronger strengthening of the interhemispheric SST gradient over the Atlantic than GR2 and GR4. Interestingly, GR1 and GR3 are the groups that project an increase in Sahel precipitation (Fig2a and Fig2c). This result is consistent with Park et al. (2015), who have shown that the strengthening of this inter-hemispheric gradient is one of the main causes of the models discrepancies in Sahel precipitation changes.

The low-level warming leads to stronger temperature gradients in GR1 and GR3 than in GR2 and GR4. This is consistent with a stronger increase in low-level winds and decrease in SLP, leading to larger increases in Sahel 
precipitation in GR1 and GR3 than in GR2 and GR4. The land-ocean temperature gradient increases in all the group of models and cannot explain the decrease in precipitation for GR4 and the very weak increase for GR2.

This difference in projected Sahel precipitation may be due to the upper-level wind dynamics, represented by the Tropical Easterly Jet (TEJ) and the African Easterly Jet (AEJ), which are known to influence Sahel precipitation (Nicholson, 2008). A southward shift of the AEJ displaces the rain-belt southward, reducing the rainfall over the Sahel (Grist and Nicholson, 2001) and the TEJ strength is significantly correlated with Sahel precipitation (Grist and Nicholson, 2001). According to Cook (1999) and Patricola and Cook (2008), the AEJ can also reduce rainfall by transporting moisture away from the Sahel. The impact of the AEJ and TEJ on the precipitation change is however not straightforward. Precipitation impacts soil moisture and surface warming, leading to a change of the meridional gradients of surface moisture and temperature that displaces the AEJ (Thorncroft and Blackburn, 1999). More intense precipitation also results in a stronger local deep meridional overturning circulation with upper-level northerlies that accelerate the TEJ. A feedback therefore exists between the AEJ (TEJ) and Sahel precipitation. We thus do not conclude on a direct impact of the jets on the precipitation change.

Following this, we investigate the low to upper levels dynamics considering the latitude-height cross-sections of the zonal wind component. The Sahel domain (from $10^{\circ} \mathrm{W}$ to $10^{\circ} \mathrm{E}$ ) is selected to compute longitudinal averages. The intra-cluster mean for each group is shown in Fig. 3e-h. During the JAS rainy season, all the groups simulate a strengthening of the surface winds (from equator to $15^{\circ} \mathrm{N}$ and between 1000 to $850 \mathrm{hPa}$ ) (Fig. 3e-h). The strengthening of the westerlies is larger for GR1 and GR3, likely because of the greater warming over northern Africa (Fig. 3a and c). The low-level winds also accelerate in response to increased latent heating due to the increased rainfall and low-level moisture. At mid-level (600 to $400 \mathrm{hPa}$ ), the AEJ moves northward for GR1, as shown by the positive (negative) anomalies south (north) of the wind core at $600 \mathrm{hPa}$ and $15^{\circ} \mathrm{N}$ (Fig. 3e). No robust changes in the AEJ speed are obtained for GR3 (Fig. 3g). This could be due to the choice of the cross-section, centered on the Greenwich meridian, whereas for GR3 there is a zonal dipole of precipitation change and thus likely, a non-homogeneous zonal response. The two others groups agree on an increase in the AEJ speed and on its southward shift (negative anomalies south of the AEJ core) (Fig. 3f and h).

At upper level, the TEJ, whose core is located generally at $200 \mathrm{hPa}$, exhibits a strengthening and a displacement southwards for GR1 and GR3 (Fig. 3e and Fig. 3g). For GR2 and GR4, the TEJ speed decreases at all latitudes range. This is consistent with the increase in precipitation, as shown previously in the literature (Nicholson, 2008). 
The projected responses in T2m, SLP and zonal wind vertical structure are generally consistent among the groups of models in terms of spatial pattern, but with differing intensities (Fig. 3). The main differences are associated with different changes in the vertically-integrated moisture flux convergence, represented by the P-E budget (Fig. 2i-1). The latter are due to the competing effects of the feeding of moisture through the low-levels winds (Fig.3e-h) and the export of moisture through the mid-level winds (Fig. 3e-h). GR1 models simulate a northward shift of the monsoon flow, a weakening and a northward shift of the AEJ. On the contrary, GR2 and GR4 models simulate a strengthening of the AEJ, in consistency with a decrease in precipitation in GR4 and with no northward displacements of the monsoon system in GR2.

For GR3, there are no evident changes in mid-level winds. This group exhibits zonally contrasted changes in precipitation (increase/decrease in the central/western Sahel) and the box centered on the Greenwich meridian is not suitable for the analysis of this pattern. Therefore, in the following section 3.3, we consider two areas to characterize the projected changes: the western and central Sahel (Fig. 2a, gray boxes).

\subsection{Seasonal cycle}

The increase in precipitation noted in Fig 2a-d may be associated with a change in the seasonal cycle of the WAM. For example, Biasutti (2013) showed from an ensemble of CMIP5 models that a pattern of precipitation similar to the one of GR3 is associated with a decrease in precipitation over the western Sahel in June-July, and an increase in precipitation over the central Sahel in September-October. To investigate further this question, we analyze the latitudeseasonal cycle diagrams of the water budget, zonal winds at $600 \mathrm{hPa}$ (AEJ) and $400 \mathrm{hPa}$ vertical wind velocity over the western Sahel $\left(20^{\circ} \mathrm{W}-0^{\circ} \mathrm{E}\right)$ and central Sahel $\left(0^{\circ} \mathrm{E}-20^{\circ} \mathrm{E}\right)$ domains. Figures 5 and 6 show the projected changes in P (Fig. 5a-d, Fig. 6a-d) and P-E (Fig. 5e-h, Fig. 6e-h) over the western and central Sahel respectively. Zonal wind at $600 \mathrm{hPa}$ (Fig. 5i-1, Fig. 6i-1) and 400 hPa vertical wind velocity (Fig. 5m-p, Fig. 6m-p) changes are also displayed in the same format.

First, we analyze the changes in the seasonal cycle over the western box (Fig. 5). GR1 simulates a strong increase in precipitation from July to October over the Sahel and in boreal winter south of the equator (Fig. 5a). This change is associated with an increase in moisture convergence (Fig. 5e), a monsoon system located northward in JAS, as shown by the northward shift of the AEJ (Fig. 5i), and with ascending (subsiding) anomalies north (south) of $10^{\circ} \mathrm{N}$ 
(Fig. 5m). GR2, GR3 and GR4 project a decrease in $\mathrm{P}$ over the Sahel (Fig. 5b-d), but the timing in $\mathrm{P}$ changes is different, varying from the March to August period for GR2 to the July to October period for GR4. These changes are associated with a decrease in moisture flux convergence (Fig. 5f-h) and with an increase in the AEJ strength (Fig. 5j-1). There is an evident subsiding anomaly for GR2, GR3, and GR4 (Fig. 5n-p). These findings obtained for GR2, GR3 and GR4 (i.e., a decrease in rainfall over western Sahel, subsidence anomalies and AEJ speed increases) are consistent with Monerie et al. (2012; 2013) and James et al. (2015).

On the central Sahel, an increase in precipitation is seen from July to December for GR1 (Fig. 6a), GR2 (Fig. 6b) and GR3 (Fig. 6c). GR4 exhibits a decrease in precipitation from April to October and an increase at the end of the year. A wetter Sahel during the late rainy season appears to be a robust feature of climate change, as shown in Biasutti (2013), Seth et al. (2013) and Kitoh et al. (2013). The moisture flux convergence given by P-E is consistent with these precipitation changes (Fig. 6e-h), except for GR2, for which there is no robust change, suggesting that precipitation change is closely related to the change in local evapotranspiration and thus in moisture recycling (Fig. 6f). The increase in precipitation at the end of the rainy season could also be associated with a delay in the phase of the Atlantic SST seasonal cycle (Biasutti and Sobel, 2009; Dwyer et al., 2014).

The zonal wind associated with the AEJ weakens and shifts northward during the entire year for GR1. This is consistent with an increase in Sahel precipitation, as shown in Grist and Nicholson (2001) for the anomalous wet years. The AEJ also shifts northward in GR2, GR3 and GR4 from October to January (Fig. 6i-lf). The AEJ strengthens in JAS for GR2 and GR4, which are projecting a decrease in precipitation during this season. GR3 does not exhibit any robust change of the AEJ speed in JAS. The $400 \mathrm{hPa}$ vertical velocity field shows a northward shift of the location of the air ascendance, and thus of the monsoon system from August to September for GR1, GR2 and GR3 (Fig. 6mno). There is also a weak negative anomaly of $400 \mathrm{hPa}$ vertical velocity in September-October for GR4 (Fig. 6p).

In summary, three groups (GR2, GR3 and GR4) project a decrease in precipitation over the western Sahel (associated with a strengthening of subsidence and AEJ speed), but the timing throughout the year is different. Three groups (GR1, GR2 and GR3) also exhibit a northward shift and a strengthening of the monsoon system in SeptemberOctober. The decrease (increase) in precipitation over the western (central) Sahel is thus a robust behavior in the CMIP5 simulations. The precipitation change is more robust in May-June-July and September-October than in July-AugustSeptember when focusing on a particular domain. The spread is thus stronger in JAS and for the entire Sahel. 


\section{Selecting a subset of models representative of the CMIP5 ensemble}

In the previous sections, four groups of models have been defined and studied in terms of Sahelian precipitation changes. They are characterized by very different precipitation responses, which indicate that it is not straightforward to select a subset of few models representative of the full CMIP5 ensemble. This is of particular importance from a practical point of view for many applicative studies (McSweeney et al., 2012; 2015; Buontempo et al., 2015). It is indeed virtually impossible for most dynamical downscaling studies or impact studies, that generally require high temporal and spatial resolutions, to deal with the entire CMIP5 ensemble, because of limitations in computing resources and/or data storage and treatment capacity.

For example, Guan et al. (2015) have shown that daily values of precipitation are needed for impact studies on crop yields since they strongly depend on the rainfall frequency and intensity, and on the timing and duration of the rainy season. As in most impact studies, it is preferable in this case to use Regional Climate Models (RCMs) than GCMs (Vizy and Cook, 2012; Crétat et al., 2014; Sylla et al., 2015) because of the higher spatial resolution (Wehner et al. 2010; Li et al. 2011) and improved convective schemes (Li et al., 2012). Because RCMs are very computationally expansive and require large amount of data as input, it is very difficult to downscale all the GCMs to take into account all the uncertainties. It would also be difficult to deal with all the necessary associated simulations with crop models.

In practice, most impact or dynamical downscaling studies are therefore based on a limited sample of GCMs. The choice of GCM is very important, in order to avoid biases in the characterization of the climate change signal and/or the uncertainties due to climate models. The selection of GCMs is however in practice often ad-hoc and not necessarily based on solid scientific ground.

In this section we propose and test several approaches to select a few models within the whole CMIP5 ensemble considered in this work. The selection of a sub-ensemble of models is often based on their performance in simulating the mean climate in present conditions, characterized by a given metric, by comparing models to observations (e.g. Lee and Wang, 2014). This approach assumes, at least implicitly, that the reliability of future projections is linked to the accuracy of the models in simulating the current climate. However, this relationship is not straightforward. To investigate this issue, we first focus on the model mean errors in Sahel precipitation and air surface temperature.

In a second stage, we will also explore alternative methodologies for model selection, based only on the models' projections (section 4.2 and section 4.3) and on the classification presented in Figure 1. 


\subsection{Relationship between the mean model biases and the projected response}

328

In this section, we study whether the different groups of models that have been defined based on future precipitation changes are characterized by different biases in the present climate.

Figure 7 shows the JAS differences between the observations (GPCP) or reanalysis (ERAI) and the intra-group mean for the four groups of models (Fig. 1). The differences with GPCP precipitation are computed on the 1979-1999 period and are shown in Figure 7a-d. The four groups show similar precipitation biases with the ITCZ located too south, resulting in a positive (negative) bias of rainfall over the Gulf of Guinea (western Africa). GR1, GR2, GR3 and GR4 are characterized by robust negative biases, with some differences in the magnitude of the biases.

Figure 7e-h shows the global T2m biases compared to ERAI on the 1979-1999 period in JAS. In the Tropical Atlantic region, biases are generally similar for each group of models. A cold bias is present over the Northern Hemisphere oceans, and also over the north of Africa. The Tropical Atlantic ocean shows a strong bias $(>+3.5 \mathrm{deg} C$ in the southeastern part), due to an incorrect representation of the Atlantic cold-tongue in JAS, as reported in Okomura et al. (2011) and Richter and Xie. (2008), and also to deficiencies in simulating continental precipitation and surface winds (Richter et al. 2012). It has been shown that the WAM is linked to the surface temperature gradient between the Sahara and the Gulf of Guinea (Nicholson et al., 2013), which is too weak in climate models and this forces the WAM system to be located too southward. Warm North Atlantic SSTs are also linked to larger precipitation (Martin et al., 2014). The biases are spatially similar in the four groups of models, but with different intensities. In particular, a colder North Atlantic is depicted by GR2 models, consistent with a stronger dry bias over the Sahel (Fig. 7f).

In summary, slight differences in mean biases in precipitation and $\mathrm{T} 2 \mathrm{~m}$ can be found among the four groups of models, in particular over the Atlantic Ocean and the Sahel. It is however difficult to interpret the inter-group differences in terms of response (characterized in section 3) to global warming based on present-day biases. Figure 8 shows an alternative classification of the 30 CMIP5 models considered in this work (32 climate models minus the two outliers), but in this case based on the correlation amongst the 30 spatial patterns of present-day errors in Sahel precipitation using GPGP as reference. Models belonging to the same group for the projections-based classification (Fig. 1) are indicated by the same color code in Figure 8. The two classifications lead to very different clusters, suggesting that the spatial structure of the projected changes are not directly related to the model mean biases for Sahel precipitation, as 
also found in Knutti et al. (2010) in a different context. This analysis confirms that the present-day biases in precipitation and temperature are not good metrics of the respective credibility of the models in terms of future precipitation changes, for this particular case.

The intensity of the biases might be different with another references. The warm bias in the equatorial Atlantic and the cold bias in the North Atlantic are however systematic (Roehrig et al., 2013) and are partly responsible for the systematic southward shift of the ITZC in coupled models (Richter and Xie, 2008). We thus argue that the main conclusion of the this section is not sensitive to the choice of the reanalysis.

It has been shown that variations in Sahel precipitation are related to SSTs anomalies over the North Atlantic (Knight et al., 2006; Zhang and Delworth, 2006; Ting et al., 2009; Mohino et al., 2011; Martin et al., 2014), the Indian Ocean (Bader and Latif, 2003), and the Mediterranean Sea (Rowell, 2003; Fontaine et al., 2010; Gaetani et al., 2010; Polo et al., 2011). It is also known that future precipitation changes in Sahel may be influenced by changes in SST (Hoerling et al., 2006; Giannini et al., 2010; Park et al., 2015). Sahel precipitation change in a given model might therefore be affected by how this particular model simulates the teleconnections with SSTs over near and remote oceans. This metric has already been used to select the "best" models in larger ensemble (Gaetani and Mohino, 2013; Martin et al., 2014). However, this methodology presents a caveat: Sahel-SSTs teleconnections are not stationary (Fontaine et al., 2011a), and the results may depend on the reference period used to compute the teleconnection. Furthermore, the teleconnections can be also affected by global warming. For this reason, we have decided not to use this metric for model selection.

\subsection{Model selection based on the classification of the projected response}

The metrics based on models present-day performances tested in section 4.1 are not suitable to select a subsample of models to study future precipitation changes in the Sahel, as the responses to anthropogenic forcing are not necessarily connected to present-day biases. Here we propose other approaches that only use the information from future climate projections. The aim of the model selection is then to select a sub-sample of models considered more realistic: i) to define a small sub-ensemble of models, ii) with an ensemble mean of precipitation changes in the Sahel comparable to the one of the full ensemble and/or iii) that correctly captures the inter-model spread of the full CMIP5 
ensemble. Two metrics are thus defined: the mean precipitation change in the Sahel, computed as the multi-model ensembles average, and the inter-model spread, defined as the multi-model standard deviation computed locally for each grid point within the domain.

Based on the previous classification (section 2.2), we propose three different approaches for model selection:

(1) A "pattern selection" method that consists in the selection of models that simulate a pattern of precipitation change of particular interest. For example, it may be useful to select a sub-sample of models whose precipitation change pattern is as close as possible to the CMIP5 multi-model mean. Models in GR3 match this condition, since the GR3 intra-group mean is the dominant response in the full CMIP5 ensemble. We therefore test this method with the GR3 models.

(2) A "diversity" method based on the random selection of models within the four groups, with the same number of models selected in each group. This method aims to keep the large range of responses from the full CMIP5 ensemble.

(3) - A "random" method that consists in the simple random selection of a subset of models from the entire CMIP5 ensemble, without taking into account the classification in four groups. Contrary to (1) and (2), this approach does not require a preliminary analysis and is not associated with particular variables and/or domains of interest. It could be used as a baseline selection approach to assess the improvement of the other subsampling methods based on the model classification described above (the "pattern selection" and "diversity" method).

The three approaches are tested for sub-samples of 4 and 8 models respectively. The results are compared to the CMIP5 multi-model mean change (computed from the RCP85-HIST differences of the 30 CMIP5 models). To ensure the robustness of the results, the model selection is carried out $n$ times following a Monte Carlo procedure; hence $n$ ensemble means are computed. Here we chose $n=30000$ for the subsample of 4 models (there are 27405 combinations of 4 models selected within 30); and $n=500000$ for 8 models (there are almost 6 million combinations of 8 models but $n$ is kept lower for computational reasons). From the $n$ realizations, we can then build a probability distribution function that determines if the new sub-ensemble averages present an anomaly of the same sign as the whole CMIP5 multi-model mean. The anomaly is considered as robust when at least 95\% of the $n$ ensemble-means 
(from 4 or 8 models) agree on the sign of the whole CMIP5 multi-model mean change.

418 The results of the 3 sub-sampling approaches for 4 and 8 models are shown in Figure 9. With 4 models, the "pattern

419 selection" method reproduces fairly well the pattern of precipitation change of the full ensemble (Fig. 9a). Less successful, the "diversity" and the "random" methods reproduce the increase in precipitation only over the central Sahel (Fig. 9bc). The same conclusions can be drawn for the sub-ensemble of 8 models, but with an agreement on more grid points compared to the 4 models sub-ensemble (Fig. 9d-f).

After this first analysis, the "pattern selection" method (based on GR3) is the most successful since it reproduces both the increase in precipitation over the central Sahel and the decrease in precipitation over Senegal.

We investigate now whether it is also the case for the inter-model spread, by computing the difference between the average of the $n$ spreads from the $n$ Monte Carlo tests and the full CMIP5 inter-model spread (in color in Fig. 9g-1). The "diversity" and the "random" methods lead to a spread very similar to the one of the full CMIP5 ensemble, both for the 4 models (Fig. 9gi) and 8 models (Fig. 9jl) subsets. The "pattern selection" clearly underestimates the spread of the full CMIP5 ensemble (more than 30\% over West Africa), and especially over the Western Sahel and the Gulf of Guinea (more than 60\%). This could be expected since the "pattern selection" approach only selects the models whose precipitation change pattern is similar to the one of the full CMIP5 ensemble, which leads to a large underestimation of the full inter-model spread.

The standard deviation of the $n$ spreads is also shown (purple contours). This is a measure of the robustness of the spread generated by all the Monte Carlo realizations for the 3 approaches. Figure $9 \mathrm{~g}-1$ shows that the "spread of the $\mathrm{n}$ spreads" is similar among the methods (none of the methods produces dramatically stronger inter-ensemble spread).

In summary, the most successful approach turns out to be the "diversity" method that i) captures correctly the mean precipitation changes over the Sahel of the full ensemble with only 4 models and ii) leads in average to an inter-model spread comparable with the one from the full CMIP5 ensemble. 
We have shown that our model classification can be useful as a basis of the "diversity" method for model selection. However, this does not guarantee that a particular sub-sample of either 4 or 8 models obtained with the "diversity" approach would be the optimal one to capture both the mean pattern and inter-model spread of the whole CMIP5 ensemble. In this section we provide the optimal sub-sets of models (4 or 8) representative of the full CMIP5 ensemble. As previously discussed, this could be very practical for dynamical downscaling studies on the Sahel interested by precipitation changes, and also impact-oriented analyzes. It is also interesting to investigate if the 4 or 8 models from the optimal ensemble belong to the same group, or to different groups amongst the 4 identified in this work.

To find the optimal subsets we use the "random" selection approach described in section 4.2 in which $n$ random selections of 4 or 8 models (30000 for 4 models and 500000 for 8 models) are done. We define a metric that evaluates both the similarity of each sub-sample of models with the full ensemble in terms of mean precipitation change pattern $\left(\mathrm{M}_{\mathrm{CMIP5}}\right)$ and spread $\left(\mathrm{SP}_{\mathrm{CMIP5}}\right)$ in JAS. For each random sample of 4 or 8 models we calculate the mean precipitation change (RCP85-HIST, named $\mathrm{M}_{\mathrm{n}}$ ) and its inter-model spread $\left(\mathrm{SP}_{\mathrm{n}}\right)$. We consider a Sahelian box (gray box in Fig. 10a) as a target to evaluate the similarity to $\mathrm{M}_{\mathrm{CMIP5}}$ and $\mathrm{SP}_{\mathrm{CMIP5}}$ the ensemble mean and spread of the full ensemble. Then we compute the spatial root-mean-square error (RMSE) between $\mathrm{M}_{n}$ and $\mathrm{M}_{\mathrm{CMIP5}}$ and $\mathrm{SP}_{\mathrm{n}}$ and $\mathrm{SP}_{\mathrm{CMIP5}}$ within the Sahelian box. This leads to $\operatorname{RMSE}\left(\mathrm{M}_{n}\right)$ and $\operatorname{RMSE}\left(\mathrm{SP}_{n}\right)$ respectively. The metric $\left(\mathrm{F}_{n}\right)$ is then defined as the sum of both standardized $\operatorname{RMSE}\left(\mathrm{M}_{\mathrm{n}}\right)$ and $\operatorname{RMSE}\left(\mathrm{SP}_{\mathrm{n}}\right)$. The final metric, $\mathrm{F}_{\mathrm{n}}$, allows sorting the $n$ sub-ensemble of models from the "best" sub-ensemble of models that exhibits the minimum value of $F_{n}$ to the "worst" sub-ensemble of models.

Figure 10 shows the $\mathrm{M}_{\mathrm{CMIP5}}-\mathrm{M}_{\mathrm{n}}$ and $\mathrm{SP}_{\mathrm{CMIP5}}-\mathrm{SP}_{\mathrm{n}}$ differences for the "best" and "worst" sub-ensemble of 4 (left) and 8 models (right). Fig. 10a-d shows that the "best" sub-set of 4 (Fig. 10ac) and 8 (Fig. 10bd) models simulates future changes much closer to $\mathrm{M}_{\mathrm{CMIP}}$ than the "worst" sub-ensemble. This is also the case for the inter-model spread, when comparing Figures $10 \mathrm{eg}$ and 10.fh. The results are better with 8 models than with 4 models (Fig. 10ab and Fig. 10ef) indicating that a too small sub-sample of models could limit the possibility of representing accurately $\mathrm{M}_{\mathrm{CMIP5}}$ and $\mathrm{SP}_{\text {CMIP5}}$.

The "best" (in the very limited sense previously described) sub-ensembles are composed by bnu_esm, mpi_esm_mr, giss_e2_r and hadgem2_cc for 4 models; and by giss_e2_r_cc, ccsm4, mpi_esm_lr, cnrm_cm5, bcc_csm1_1, miroc_esm, cesm1_bgc and haadgem2_cc. The worst sub-set of models are miroc_esm, miroc_esm_chem, miroc5 and the csiro_mk3_6_0 for 4 models, and gfdl_cm3_0, csiro_mk3_6_0, cnrm_cm5, miroc_esm, bnu_esm, fgoals_g2, miroc_esm_chem and miroc5 for 8 models. 
475 Based on Fig. 1 the "best" sub-ensemble of 4 models contains one model from GR2, two from GR3 and one from GR4, 476 whereas the "best" sub-ensemble of 8 models is built from 2 models from GR1, 1 from GR2, 3 from GR3 and 2 from 477 GR4. This may seem contradictory to the results from the previous section, which concludes that the "diversity" 478 approach is the more appropriate to define a sub-ensemble of models. This can be explained by the fact that we have 479 selected in this section only the optimal sub-sets with the best performing $F_{n}$ metric. However, if we examine the 480 probability density function of $F_{n}$, we find that most subset of models associated with values of $F_{n}$ included in the tenth 481 percentile correspond to subset of models in which one model of each of the 4 groups is selected (not shown). On the 482 contrary, regarding the $90^{\text {th }}$ percentile of $F_{n}$, the worst sub-ensembles are generally obtained when there is an over483 representation of one group of models (for example, the "worst" ensemble of 8 models is composed by the five GR1 484 models). 


\section{Conclusion}

Current climate models show large uncertainties in future projections of the WAM and Sahel precipitation, sometimes even opposite responses. In the first part of this work, we classified the future Sahel precipitation projections from 32 CMIP5 models to define four groups of models, which allowed us to extract the main types of model responses to facilitate their physical characterization and analyze their robustness. In the second part of the study, we used the previous classification and different methodologies to identify sub-sets of 4 or 8 models (amongst 30 CMIP5 models) representative of the full ensemble, in terms of the ensembles mean and inter-model spread. The aim is to be able to provide to other communities (e.g. statistical and dynamical downscaling, impact modelers) a reduced but meaningful set of models, much more easy to manage, to facilitate their applicative research.

Concerning the CMIP5 models classification and the characterization of the main responses over the Sahel, our findings can be summarized as follows:

- The methodology for model classification is based on a hierarchical clustering algorithm (Jain et al. 1999). The similarity criterion is based on the spatial pattern of precipitation change, defined as the differences RCP85 (2060 -2099) minus HIST (1960-1999) in JAS. We obtained four groups of models (GR1-GR4) with robust intra-group pattern of precipitation changes. They are characterized by robust and specific changes in precipitation, water budget, temperature and atmospheric dynamics.

- GR1 shows a large and robust increase in precipitation over the entire Sahel in JAS. GR2 exhibits a moderate increase in precipitation over the central Sahel. GR3 projects a decrease in precipitation over the western Sahel and an increase over the central Sahel. Finally GR4 projects drier conditions over the entire Sahel. This large variety of precipitation changes is consistent with other studies based on CMIP-type ensembles, as summarized in the review of Druyan (2011) for the CMIP3 models. We show that, in the climate change context, the Sahel precipitation response is not spatially homogeneous. The western Sahel is projected to become drier in three groups of models (GR2, GR3 and GR4) for the whole JAS period. Projections for the central Sahel show an increase in precipitation, especially during the months of the monsoon withdrawal (September-October) in three groups of models (GR1, GR2 and GR3).

- The increase in precipitation in the central Sahel is explained by a strong warming over the Sahara $\left(>6^{\circ} \mathrm{C}\right)$ and a strengthening of the North-Tropical Atlantic SST gradient. In GR1 and GR3 the heat low is deeper, pushing 

circulation strengthens but does not move northward. A drier western Sahel is associated with less moisture convergence and more subsidence.

- During the latest months of the rainy season (SON), the increase in precipitation over the central Sahel is driven by changes in SSTs (Biasutti and Sobel, 2009) and by an increase in local moisture recycling (that

The CMIP5 atmosphere-ocean-general circulation model (AOGCM) simulations used in this study do not take into account the dynamic vegetation and land use feedback. We should keep in mind that the Sahel experiences strong feedbacks between land and precipitations (Koster el al. 2004). This can potentially lead to a miss-estimation of projected precipitation changes, especially during the late rainy season (Wang and Alo, 2012).

Furthermore, the CMIP5 climate models suffer from several biases due to the models coarse resolution and underestimation of regional orography (Wehner et al. 2010; Li et al. 2011). The present results have thus to be confirmed with RCMs and global GCM simulations using finer grids. To do so, it is first necessary to select the GCM simulations that will be used to force the RCMs (dynamical downscaling) or that will be statistically downscaled. The selected set of global simulations has to be representative of the full CMIP5 in terms of ensemble mean and spread in Sahel precipitation change, otherwise the impact studies can not document and explore the signal and uncertainty provided by the ensemble of CMIP5 climate models. The methods for the selection of sub-sample of models tested in this study are of interest in this context. 
540 Regarding the model selection, the approaches that we propose can be applied to other areas and variables of interest. In

541 our particular case, our conclusions are:

542 - We show that over the Sahel, future precipitation changes in summer are not strongly associated with present-day 543 biases. For this reason, we propose a selection criterion based on the projections instead of on the mean historical 544 climate simulations. The objective is then not to select a subset of models judged to be more realistic, but to select a 545 small subset of models representative of the full ensemble. This could be particularly useful for studies in which 546 computational resources and/or data storage and/or treatment capacity are a limiting factor, which is the case for most 547 dynamical downscaling or impact studies.

548 - The "best" sub-ensemble of models, in terms of similarity with the full CMIP5 ensemble mean and spread, turns out to 549 be composed by the bnu_esm, mpi_esm_mr, giss_e2_r and hadgem2_cc models.

550 - In section 4.3, we propose alternative solutions that may be useful for example if data from the above mentioned models are not available at the time frequency necessary for the study of interest. They are based on the model classification presented in this work. The best method basically consist of selecting one or two models in each of the four groups, which allows more freedom in the choice of the models, and ensure a good representation of both the mean and spread of the full ensemble. When using the methods described in the section 5 for impact studies it is crucial to use consistent physical packages between RCM and the forcing GCM to ensure that the downscaled field will not be the result of a change of the parametrization but of the forcing field with a higher resolution (Saini et al., 2015). If not the downscaled fields will not be representative of the CMIP5 ensemble. 


\section{Acknowledgements}

563 We acknowledge the World Climate Research Programme's Working Group on Coupled Modelling, which is 564 responsible for CMIP, and we thank the climate modelling groups for producing and making available their model 565 output. For CMIP the U.S. Department of Energy's Program for Climate Model Diagnosis and Intercomparison 566 provides coordinating support and led development of software infrastructure in partnership with the Global 567 Organization for Earth System Science Portals. Calculations were performed using HPC resources from DSI-CCUB 568 (Université de Bourgogne). This work was supported by the EU-funded PREFACE (grant agreement 603521) project.

569 We also thank the two anonymous reviewers for their comments and suggestions.

570

571 
Figure1: The model "family tree" from CMIP5 models for the RCP85-HIST change in Sahel precipitation, shown as a dendrogram (a hierarchical clustering of the pairwise distance matrix for precipitation, see text). Models on the same branch simulate similar patterns in precipitation changes. Models from the same group share the same color.

Figure2: Projected changes in JAS (a-d) precipitation (mm.day ${ }^{-1}$ ), (e-h) evaporation (mm.day ${ }^{-1}$ ) and (i-l) P-E budget $\left(\mathrm{mm}_{\mathrm{day}}{ }^{-1}\right)$ for the four groups of models (one group per column) identified by the clustering. The present climatology (HIST) is displayed with red contours and the RCP85-HIST differences by color shading. Hatching represents the gridpoints where at least $80 \%$ of the models agree with the sign of the intra-group ensemble mean within each groups (5 for GR1; 7 for GR2; 13 for GR3; 5 for GR4)

Figure3: Projected changes RCP85-HIST in JAS (a-d) $2 \mathrm{~m}$ temperature $\left({ }^{\circ} \mathrm{C}\right.$ ) (shading), sea level pressure (hPa) (blue contours) and $950 \mathrm{hPa}$ winds $\left(\mathrm{m} . \mathrm{s}^{-1}\right.$ ) (green arrows) for the four groups of models. The winds anomalies are displayed if at least $80 \%$ of the models agree on the sign of the intra-cluster mean. (e-h) Latitude-height cross section (average from

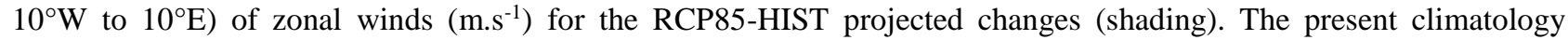
(HIST) for zonal winds is displayed with red contours. Hatching represents the grid-points where at least $80 \%$ of the models agree with the sign of the intra-cluster mean ( 5 for GR1; 7 for GR2; 13 for GR3; 5 for GR4).

Figure 4: Changes in Atlantic SST gradient, computed as the zonally-averaged RCP85-HIST difference over the Atlantic Ocean $\left(75^{\circ} \mathrm{W}-10^{\circ} \mathrm{E}\right)$ minus the SST tropical warming $\left(180^{\circ} \mathrm{W}-180^{\circ} \mathrm{E} ; 30^{\circ} \mathrm{S}-30^{\circ} \mathrm{N}\right)$ in $\mathrm{JAS}$. The intra-cluster mean is computed for GR1 (brown line), GR2 (blue line), GR3 (green line) and GR4 (red line). Shadings represent the intra-cluster standard deviation.

Figure5: Time-Latitude diagram from January to December for RCP85-HIST projected changes averaged over the western Sahel $\left(20^{\circ} \mathrm{W}-0^{\circ} \mathrm{W}\right)$ in (a-d) precipitation $\left(\mathrm{mm}^{-d a y}{ }^{-1}\right)$, (e-h) P-E (mm.day $\left.{ }^{-1}\right)$, (i-1) $600 \mathrm{hPa}$ zonal wind $\left(\mathrm{m} \cdot \mathrm{s}^{-1}\right)$ and (m-p) $400 \mathrm{hPa}$ omega $\left(\mathrm{Pa}_{\mathrm{s}}{ }^{-1}\right)$ for the four groups of models. The present climatology (HIST) is displayed with red contours and the HIST-RCP85 differences by the shading. Hatching represents the grid-points where at least $80 \%$ of the models agree with the sign of the intra-cluster mean (5 for GR1; 7 for GR2; 13 for GR3; 5 for GR4).

Figure6: Same as the figure 5 but for the central Sahel (from $0^{\circ}$ to $20^{\circ} \mathrm{E}$ ).

Figure7: Mean model bias in JAS (a-d) precipitation computed as HIST-GPCP (in mm.day ${ }^{-1}$ ) represented by the shading. Observed precipitation (GPCP) is also displayed (red contours). Mean model bias of global T2m in JAS computed as HIST-ERAI reanalysis (e-h) (in ${ }^{\circ} \mathrm{C}$ ). Hatching represents the grid-points where at least $80 \%$ of the models agree with the sign of the intra-cluster mean bias.

Figure8: The model "family tree" from the CMIP5 models for biases in Sahel precipitation, shown as a dendrogram (a hierarchical clustering of the pairwise distance matrix for precipitation). The spatial pattern used to compute the correlation matrix is the JAS precipitation bias (HIST-GPCP). Models on the same branch simulate similar biases in precipitation. Colors indicate models belonging to the clusters defined in Fig.1 according to the classification on the projected response.

Figure9: Mean precipitation changes (mm.day-1) of the 30 CMIP5 models (models in color in Figure 1b, shading) and the probability to reproduce its sign, when randomly selecting (a-c) 4 models and (d-f) 8 models (hatching). The probability is computed with a Monte Carlo approach. Hatching shows the points where at least $95 \%$ of the $n$ draws agree on the sign of the CMIP5 pattern. Here, $n$ is equal to 30000 (500 000) for 4 models (8 models). The spread of the intra-group precipitation change is computed when using (g-i) 4 models and (j-1) 8 models, the difference (in \%) between the mean spread computed from the $n$ draws and the spread of the full CMIP5 ensemble is displayed in colors and the spread computed from the $n$ values of spread is indicated by the purple lines $\left(\mathrm{mm} . \mathrm{day}^{-1}\right)$. The "pattern selection" method consists of selecting 4 or 8 models in GR3, the "random" method randomly selects 4 or 8 models within the full CMIP5 ensemble, and the "diversity" method selects 1 or 2 models from each group of models in Fig.1.

Figure10: Differences of ensemble mean JAS precipitation changes (RCP85-HIST; mm.day ${ }^{-1}$ ) between the full CMIP5 ensemble, and the best ensemble of (a) 4 models, (b) 8 models, and the "worst" ensemble of (c) 4 models and (d) 8 models. Differences of JAS mean precipitation (mm.day ${ }^{-1}$ ) between the spread of the RCP85-HIST CMIP5 data-set projection minus the spread of RCP85-HIST projection of the "best" ensemble of (e) 4 models, (f) 8 models and the "worst" ensemble of (g) 4 models and (h) 8 models. 


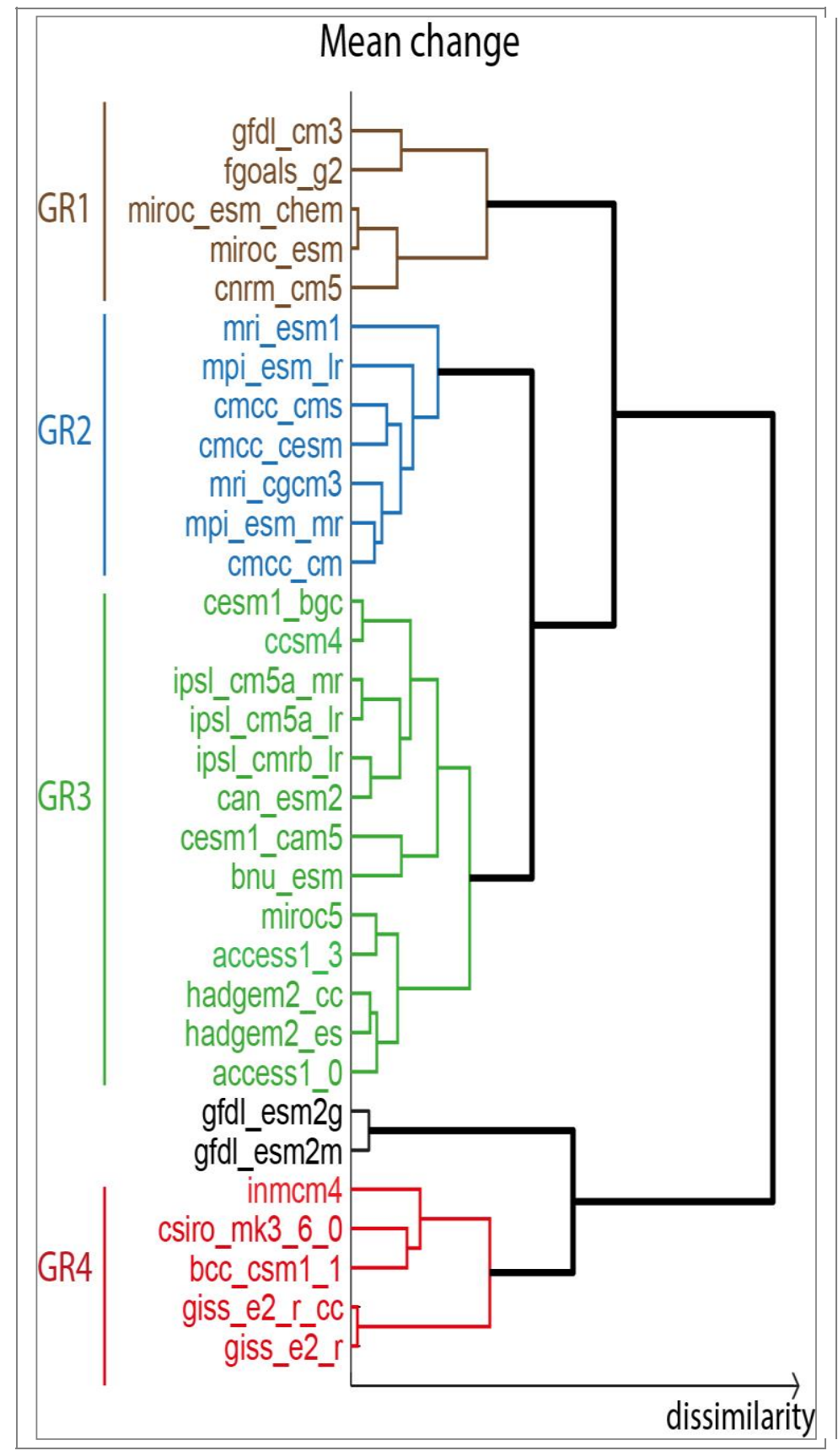

Figure1: The model "family tree" from CMIP5 models for the RCP85-HIST change in Sahel precipitation, shown as a dendrogram (a hierarchical clustering of the pairwise distance matrix for precipitation, see text). Models on the same branch simulate similar patterns in precipitation changes. Models from the same group share the same color. 

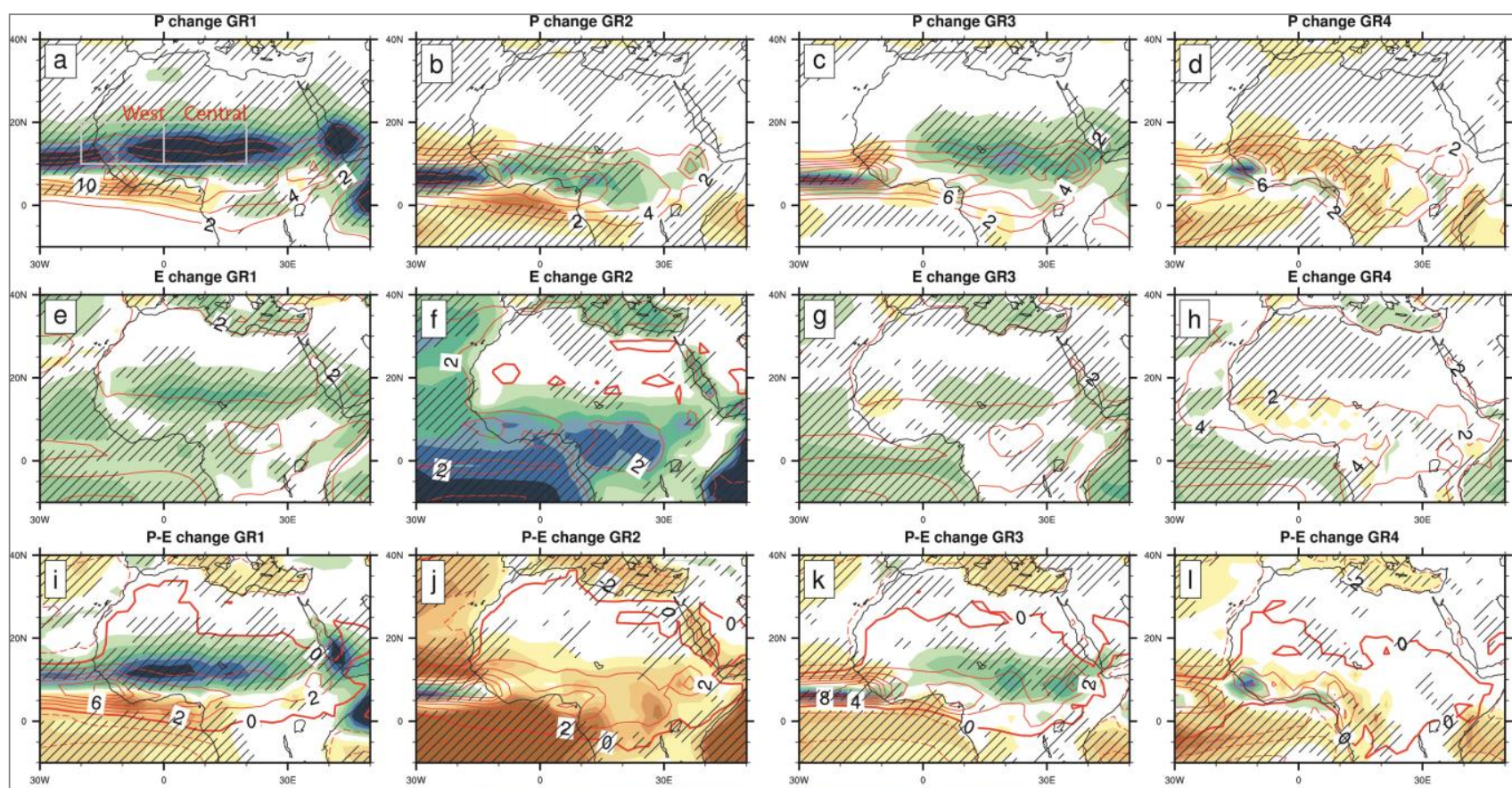

647

648

649

650

651

652

653

654

655

656

657

658

659

660

661

662

663

664

665

666

667

668

669

670

671

672

Figure2: Projected changes in JAS (a-d) precipitation (mm.day ${ }^{-1}$ ), (e-h) evaporation (mm.day ${ }^{-1}$ ) and (i-l) P-E budget $\left(\mathrm{mm}_{\mathrm{day}}{ }^{-1}\right)$ for the four groups of models (one group per column) identified by the clustering. The present climatology (HIST) is displayed with red contours and the RCP85-HIST differences by color shading. Hatching represents the gridpoints where at least $80 \%$ of the models agree with the sign of the intra-group ensemble mean within each groups (5 for GR1; 7 for GR2; 13 for GR3; 5 for GR4) 


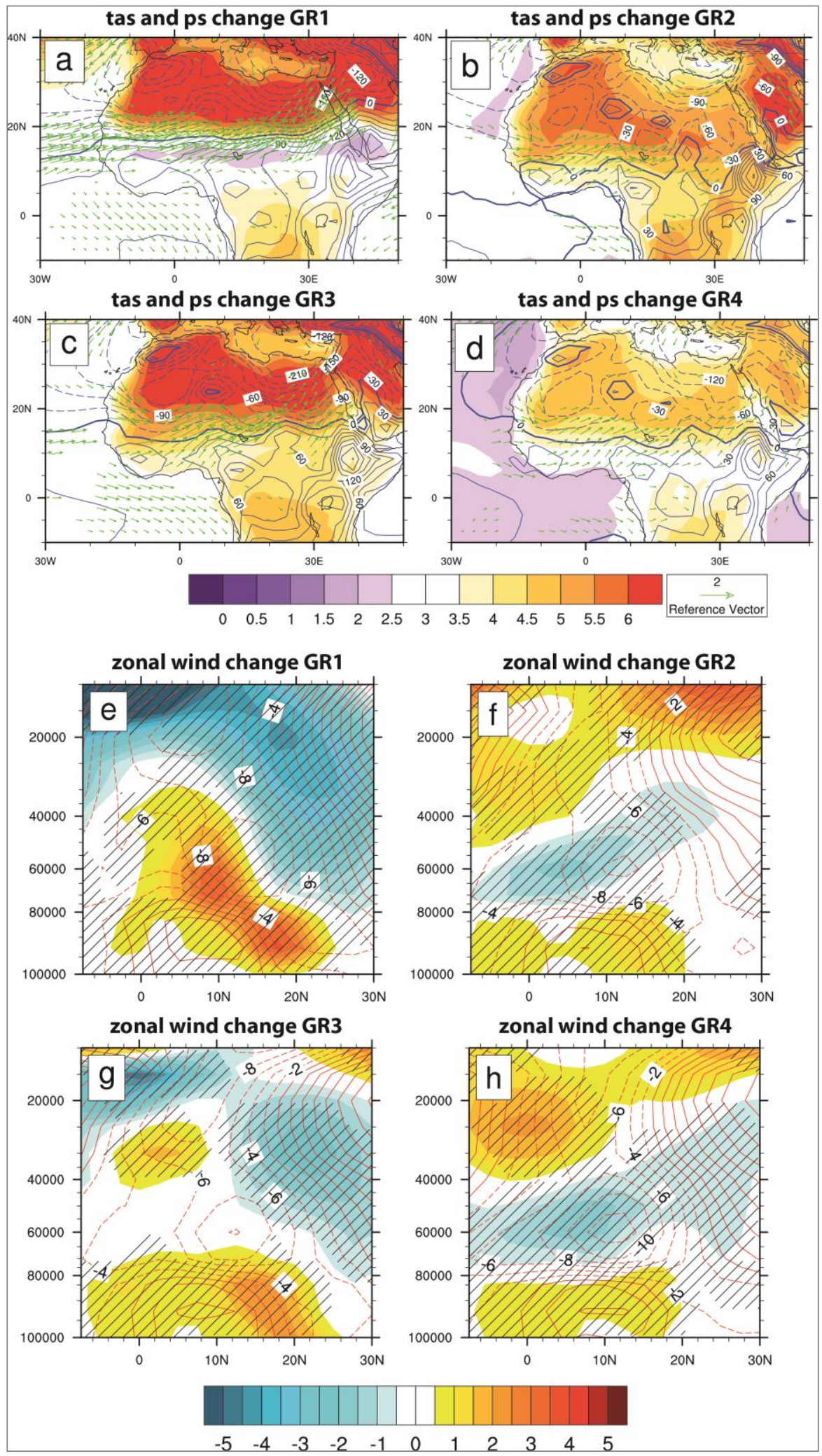

725 Figure3: Projected changes RCP85-HIST in JAS (a-d) $2 \mathrm{~m}$ temperature $\left({ }^{\circ} \mathrm{C}\right.$ ) (shading), sea level pressure (hPa) (blue 


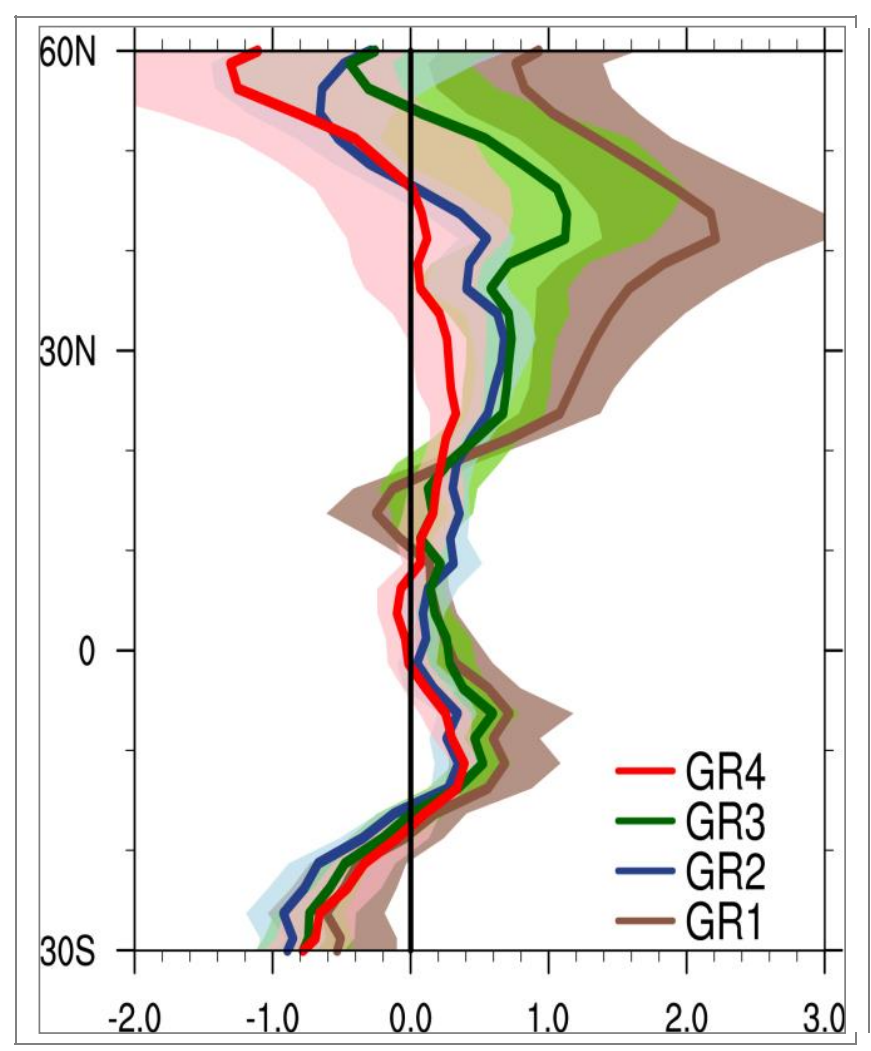

Figure 4: Changes in SST Atlantic gradient, computed as the zonally-averaged RCP85-HIST difference over the Atlantic Ocean $\left(75^{\circ} \mathrm{W}-10^{\circ} \mathrm{E}\right)$ minus the SST tropical warming $\left(180^{\circ} \mathrm{W}-180^{\circ} \mathrm{E} ; 30^{\circ} \mathrm{S}-30^{\circ} \mathrm{N}\right)$ in JAS. The intra-cluster mean is computed for GR1 (brown line), GR2 (blue line), GR3 (green line) and GR4 (red line). Shadings represent the intra-cluster standard deviation. 


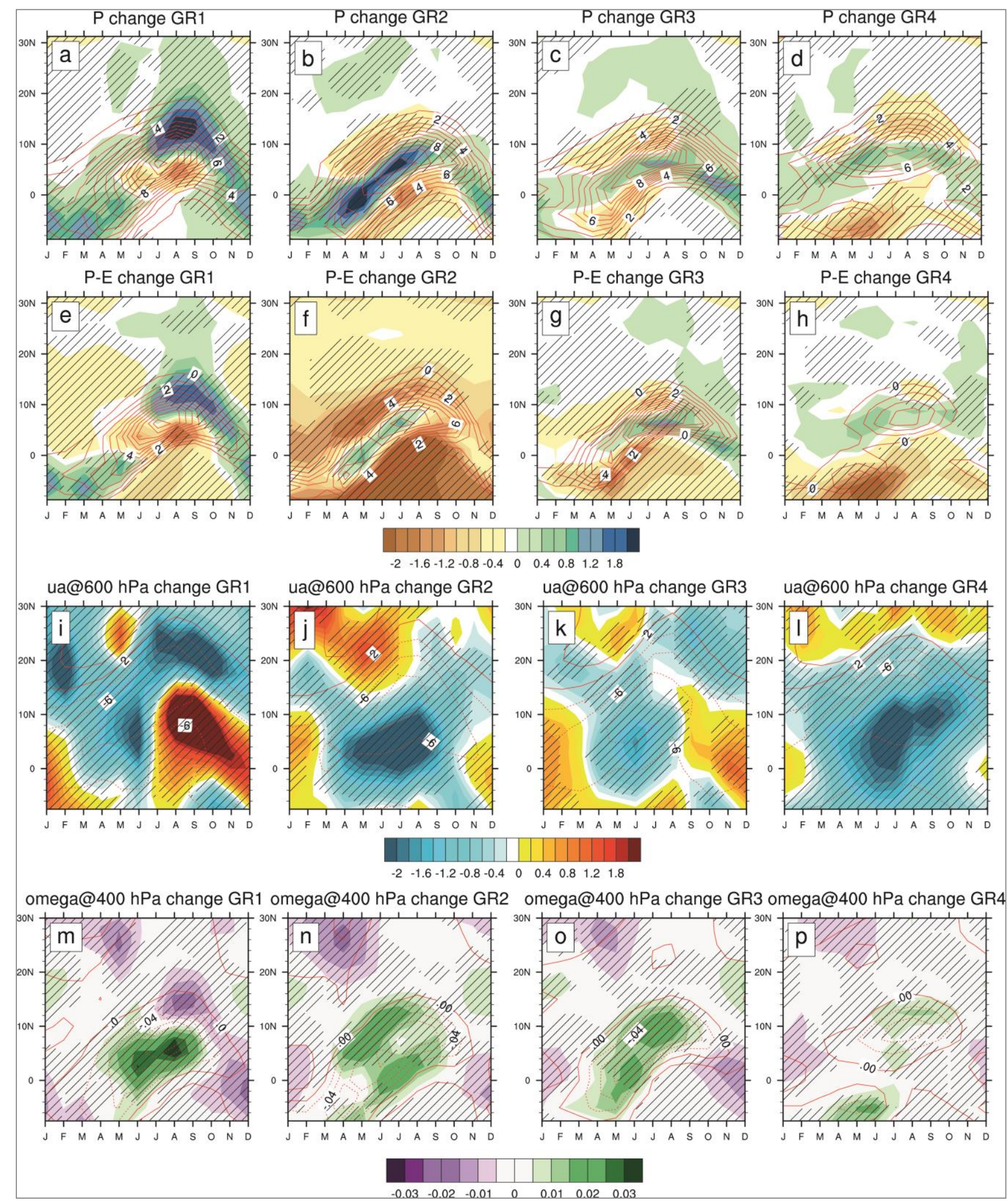

P-E change GR2

$-2-1.6-1.2-0.8-0.4$

omega@400 hPa change GR1 omega@400 hPa change GR2 omega@400 hPa change GR3 omega@400 hPa change GR4

Figure5: Time-Latitude diagram from January to December for RCP85-HIST projected changes averaged over the western Sahel $\left(20^{\circ} \mathrm{W}-0^{\circ} \mathrm{W}\right)$ in $(\mathrm{a}-\mathrm{d})$ precipitation $\left(\mathrm{mm}^{-d a y^{-1}}\right)$, (e-h) P-E (mm.day $\left.{ }^{-1}\right),(\mathrm{i}-1) 600 \mathrm{hPa}$ zonal wind $\left(\mathrm{m} . \mathrm{s}^{-1}\right)$ and (m-p) $400 \mathrm{hPa}$ omega (Pa.s $\left.{ }^{-1}\right)$ for the four groups of models. The present climatology (HIST) is displayed with red contours and the HIST-RCP85 differences by the shading. Hatching represents the grid-points where at least $80 \%$ of the models agree with the sign of the intra-cluster mean (5 for GR1; 7 for GR2; 13 for GR3; 5 for GR4). 


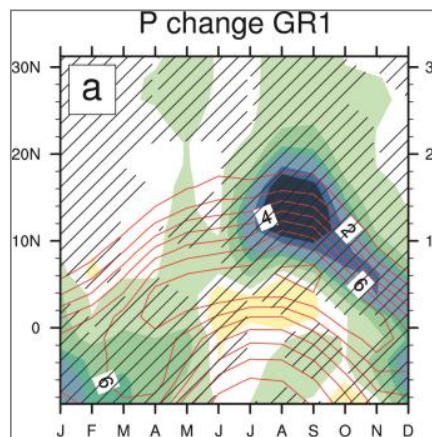

P-E change GR1

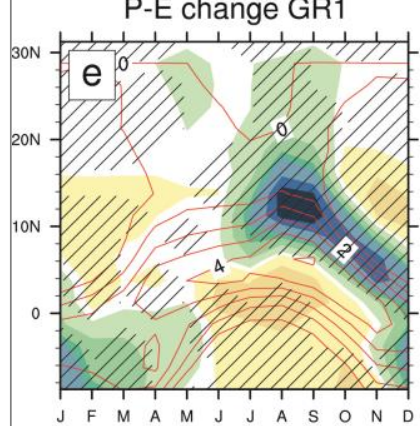

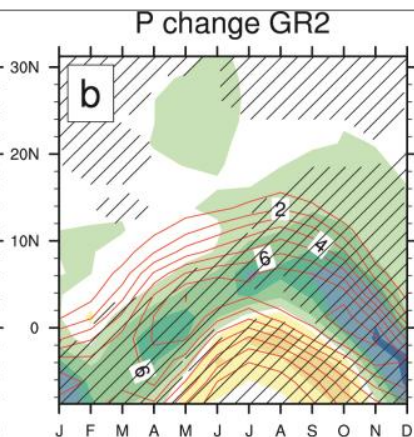

P-E change GR2

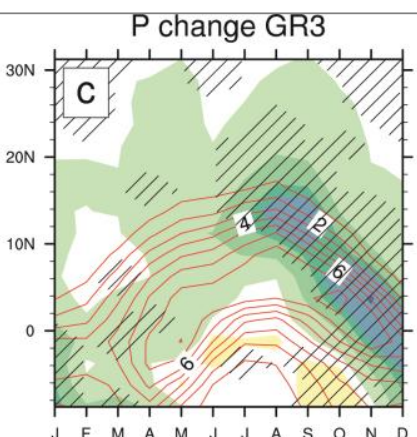

P-E change GR3

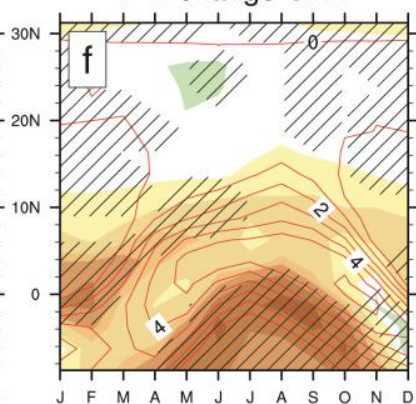

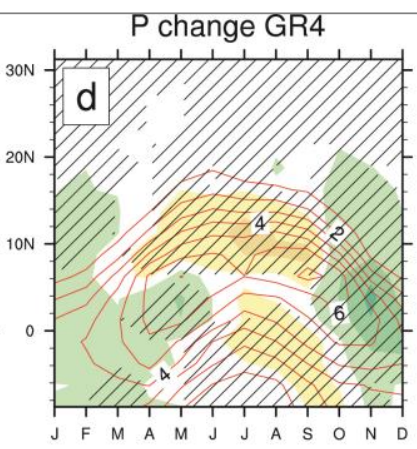

P E-change GR4

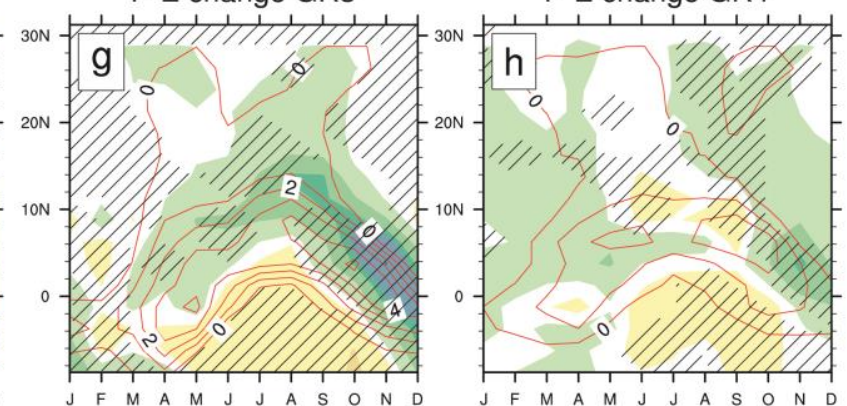

$\begin{array}{lllllllllll}-2 & -1.6 & -1.2 & -0.8 & -0.4 & 0 & 0.4 & 0.8 & 1.2 & 1.8\end{array}$

ua@600 hPa change GR1 ua@600hPa change GR2 ua@600hPa change GR3
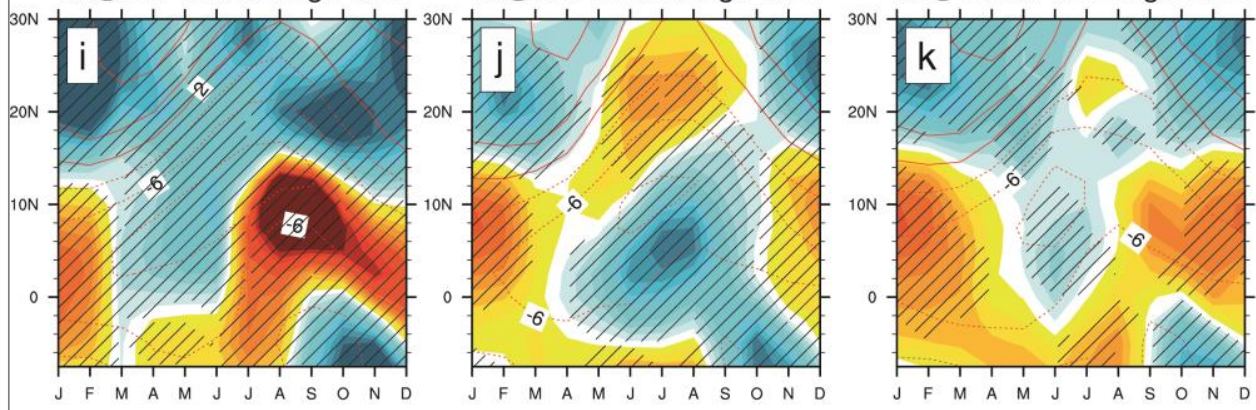

ua@600 hPa change GR4
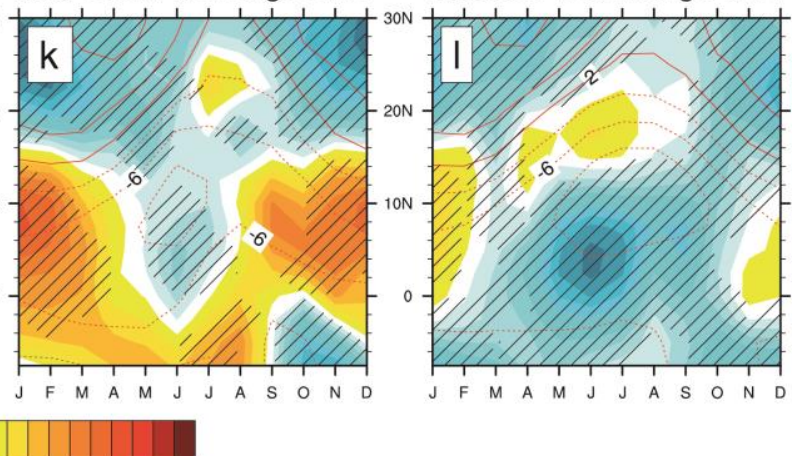

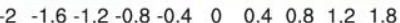

omega@400 hPa change GR1 omega@400 hPa change GR2 omega@400 hPa change GR3 omega@400 hPa change GR4
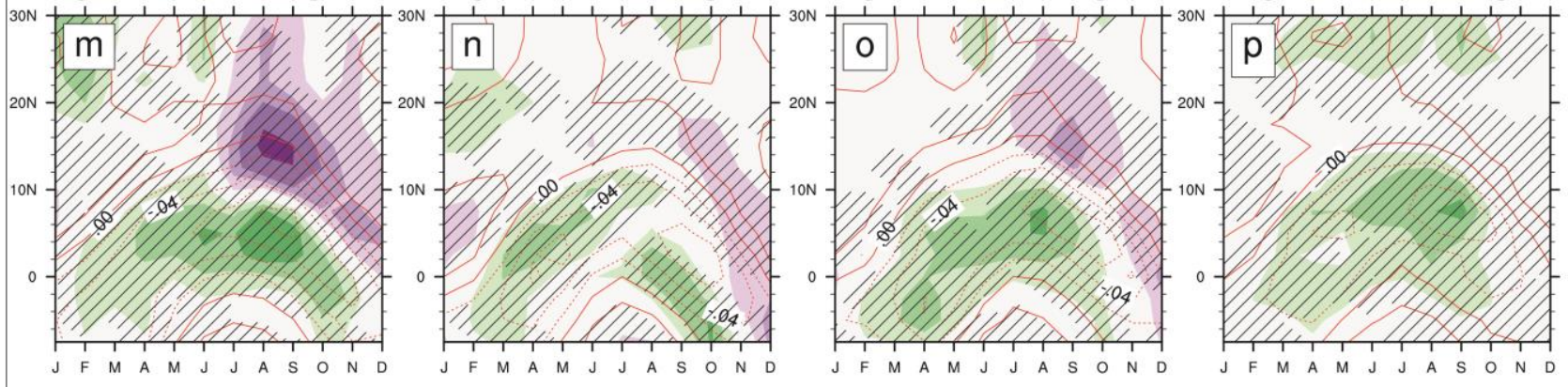

750 


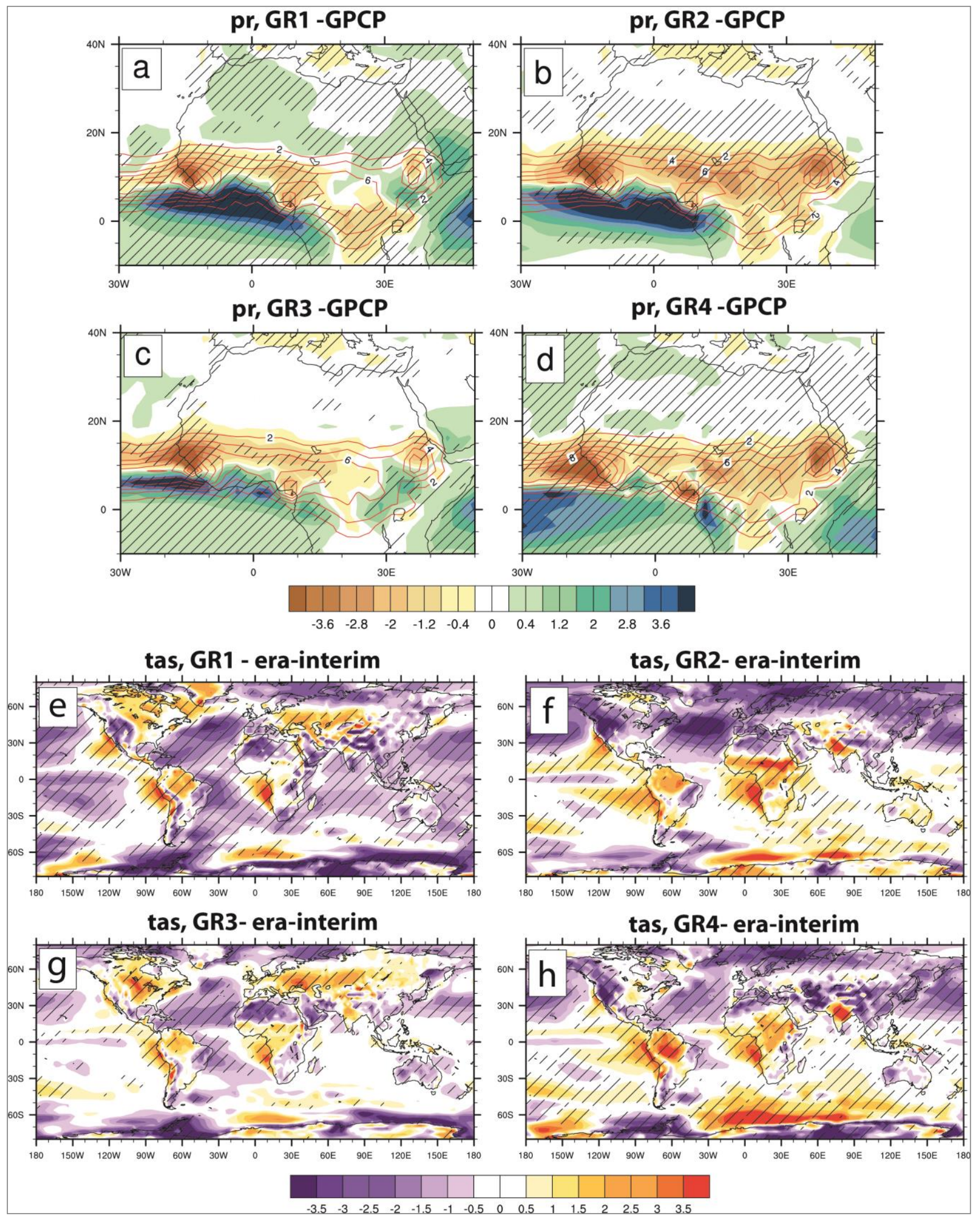

Figure7: Mean model bias in JAS (a-d) precipitation computed as HIST-GPCP (in mm.day ${ }^{-1}$ ) represented by the shading. Observed precipitation (GPCP) is also displayed (red contours). Mean model bias of global T2m in JAS computed as HIST-ERAI reanalysis (e-h) (in ${ }^{\circ} \mathrm{C}$ ). Hatching represents the grid-points where at least $80 \%$ of the models agree with the sign of the intra-cluster mean bias. 


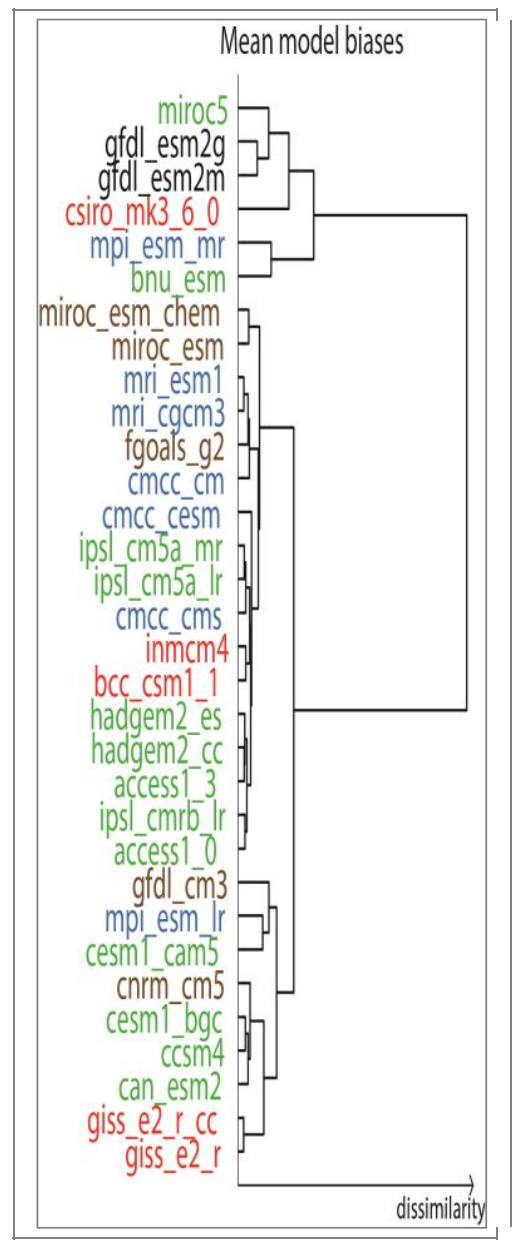

Figure8: The model "family tree" from the CMIP5 models for biases in Sahel precipitation, shown as a dendrogram (a hierarchical clustering of the pairwise distance matrix for precipitation). The spatial pattern used to compute the correlation matrix is the JAS precipitation bias (HIST-GPCP). Models on the same branch simulate similar biases in precipitation. Colors indicate models belonging to the clusters defined in Fig.1 according to the classification on the projected response. 


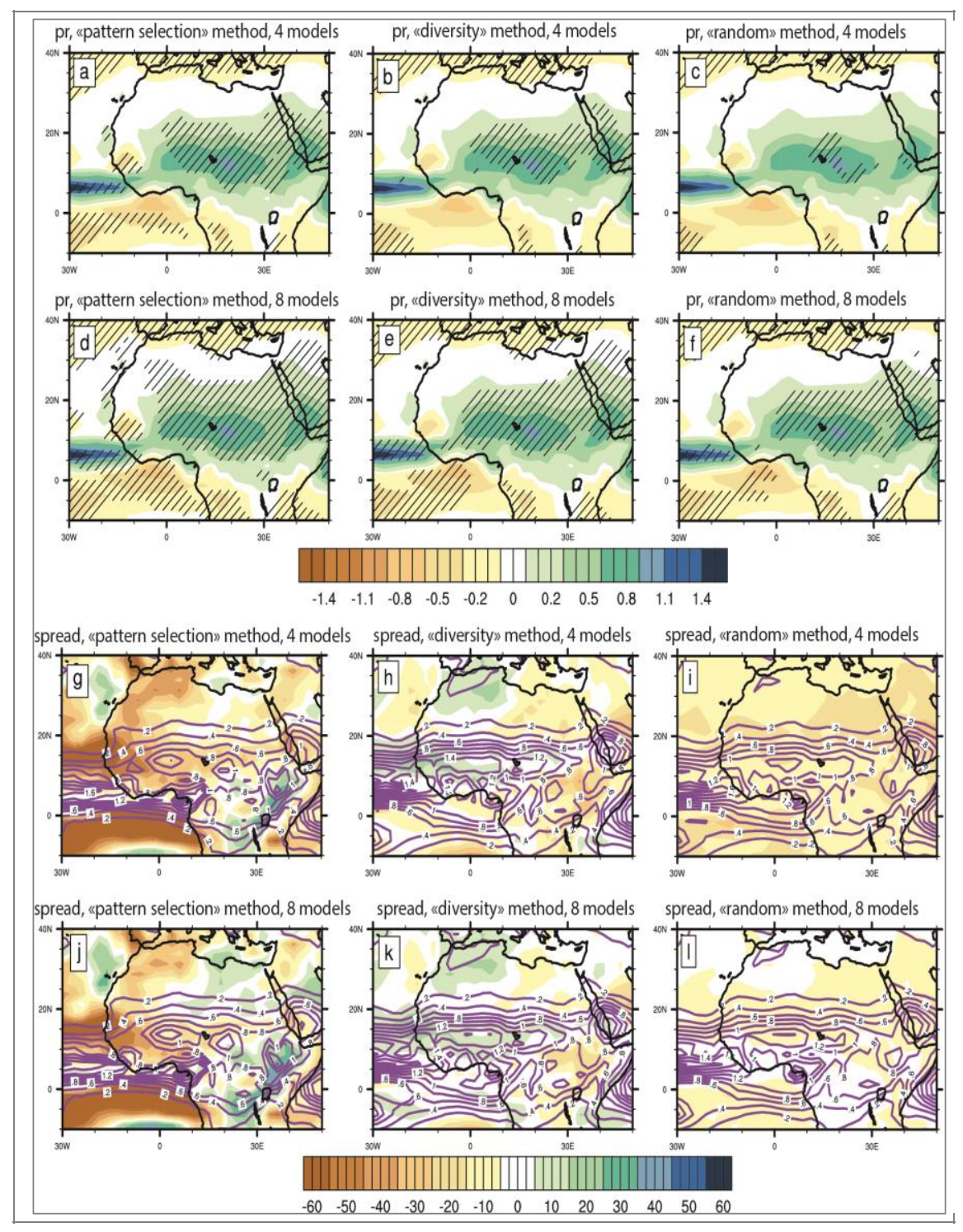

Figure9: Mean precipitation changes (mm.day-1) of the 30 CMIP5 models (models in color in Figure 1b, shading) and the probability to reproduce its sign, when randomly selecting (a-c) 4 models and (d-f) 8 models (hatching). The probability is computed with a Monte Carlo approach. Hatching shows the points where at least $95 \%$ of the $n$ draws agree on the sign of the CMIP5 pattern. Here, $n$ is equal to 30000 (500 000) for 4 models (8 models). The spread of the intra-group precipitation change is computed when using (g-i) 4 models and (j-1) 8 models, the difference (in \%) between the mean spread computed from the $n$ draws and the spread of the full CMIP5 ensemble is displayed in colors and the spread computed from the $n$ values of spread is indicated by the purple lines $\left(\mathrm{mm} \cdot \mathrm{day}^{-1}\right)$. The "pattern selection" method consists of selecting 4 or 8 models in GR3, the "random" method randomly selects 4 or 8 models within the full CMIP5 ensemble, and the "diversity" method selects 1 or 2 models from each group of models in Fig.1. 


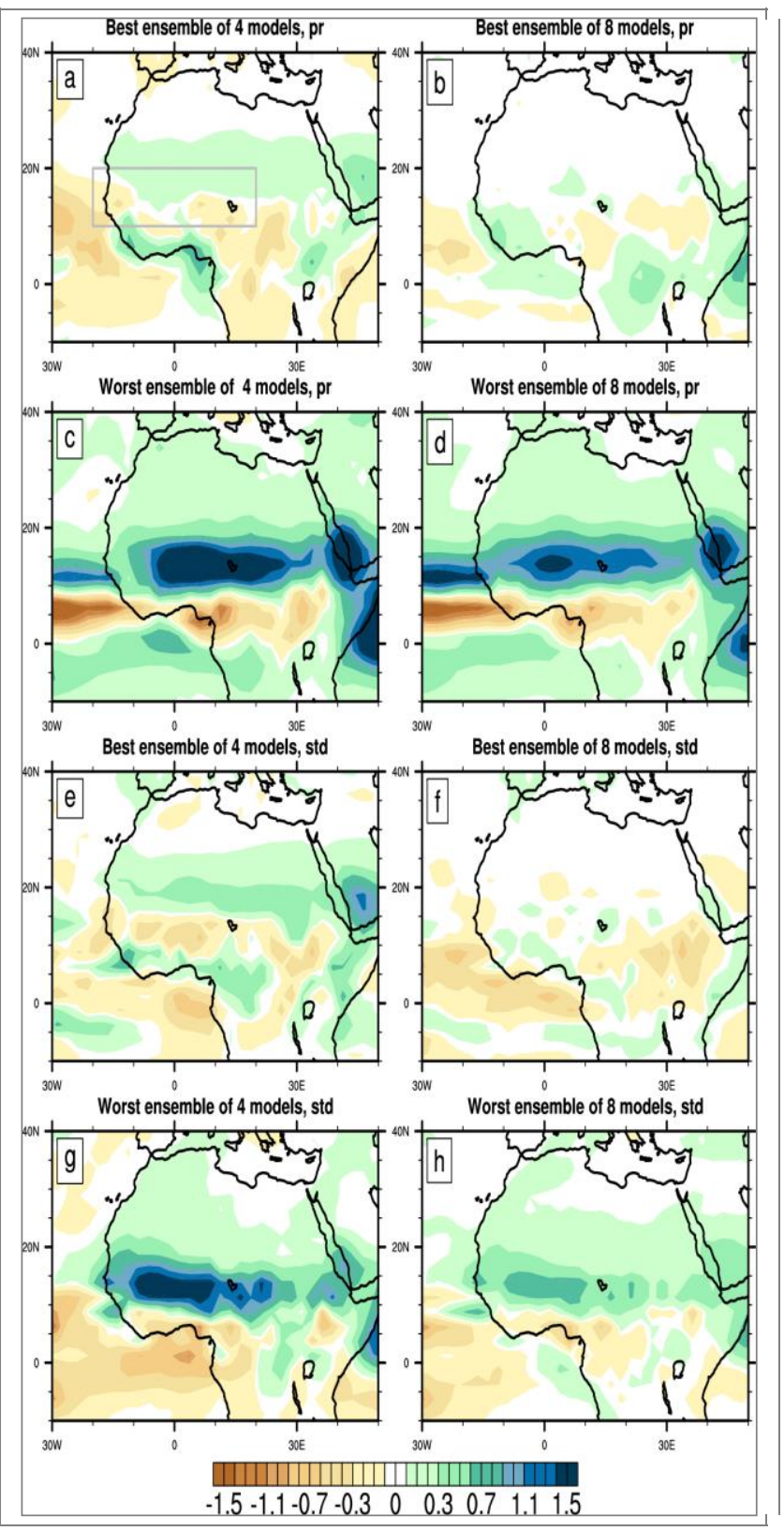

Figure10: Differences of ensemble mean JAS precipitation changes (RCP85-HIST; mm.day-1) between the full CMIP5 ensemble, and the best ensemble of (a) 4 models, (b) 8 models, and the "worst" ensemble of (c) 4 models and (d) 8 models. Differences of JAS mean precipitation $\left(\mathrm{mm}_{\text {.day }}{ }^{-1}\right)$ between the spread of the RCP85-HIST CMIP5 data-set projection minus the spread of RCP85-HIST projection of the "best" ensemble of (e) 4 models, (f) 8 models and the 814 "worst" ensemble of (g) 4 models and (h) 8 models. 


\section{References}

Abdussalam AF et al. (2014) The impact of climate change on meningitis in Northwest Nigeria: An assessment using CMIP5 climate model simulations. Weather, Climate, and Society 6:371-379

Adler RF et al. (2003) The version-2 global precipitation climatology project (GPCP) monthly precipitation analysis (1979-present). Journal of hydrometeorology 4:1147-1167

Bader J, Latif M (2003) The impact of decadal-scale Indian Ocean sea surface temperature anomalies on Sahelian rainfall and the North Atlantic Oscillation. Geophysical Research Letters 30

Bader J, Latif M (2003) The impact of decadal-scale Indian Ocean sea surface temperature anomalies on Sahelian rainfall and the North Atlantic Oscillation. Geophys Res Lett 30:2169. doi:10.1029/2003gl018426

Barros V et al. (2015) Climate change 2014: impacts, adaptation, and vulnerability. Part B: regional aspects. Contribution of Working Group II to the Fifth Assessment Report of the Intergovernmental Panel on Climate Change.

Biasutti M (2013) Forced Sahel rainfall trends in the CMIP5 archive. Journal of Geophysical Research: Atmospheres 118:1613-1623. doi:doi:10.1002/jgrd.50206

Biasutti M, Sobel AH (2009) Delayed Sahel rainfall and global seasonal cycle in a warmer climate. Geophys Res Lett 36:L23707. doi:10.1029/2009g1041303

Buontempo C, Mathison C, Jones R, Williams K, Wang C, McSweeney C (2015) An ensemble climate projection for Africa. Climate Dynamics 44:2097-2118. doi:10.1007/s00382-014-2286-2

Caminade C et al. (2014) Impact of climate change on global malaria distribution. Proceedings of the National Academy of Sciences 111:3286-3291

Cook KH (1999) Generation of the African Easterly Jet and Its Role in Determining West African Precipitation. Journal of Climate 12:1165-1184. doi:10.1175/1520-0442(1999)012<1165:gotaej>2.0.co;2

Crétat J, Vizy E, Cook K (2014) How well are daily intense rainfall events captured by current climate models over Africa? Climate Dynamics 42:2691-2711. doi:10.1007/s00382-013-1796-7

Dai A, Lamb PJ, Trenberth KE, Hulme M, Jones PD, Xie P (2004) The recent Sahel drought is real. International Journal of Climatology 24:1323-1331

Dee D et al. (2011) The ERA-Interim reanalysis: Configuration and performance of the data assimilation system. Quarterly Journal of the Royal Meteorological Society 137:553-597

Dong B, Sutton R (2015) Dominant role of greenhouse-gas forcing in the recovery of Sahel rainfall. Nature Clim Change 5:757-760. doi:10.1038/nclimate2664

Druyan LM (2011) Studies of 21st-century precipitation trends over West Africa. International Journal of Climatology $31: 1415-1424$

Dwyer JG, Biasutti M, Sobel AH (2014) The Effect of Greenhouse Gas-Induced Changes in SST on the Annual Cycle of Zonal Mean Tropical Precipitation. Journal of Climate 27:4544-4565

Fontaine B et al. (2010) Impacts of warm and cold situations in the Mediterranean basins on the West African monsoon: observed connection patterns (1979-2006) and climate simulations. Climate Dynamics 35:95-114. doi:10.1007/s00382-009-0599-3

Fontaine B, Gaetani M, Ullmann A, Roucou P (2011a) Time evolution of observed July-September sea surface temperature-Sahel climate teleconnection with removed quasi-global effect (1900-2008). Journal of Geophysical Research: Atmospheres 116. doi:10.1029/2010jd014843

Fontaine B, Roucou P, Monerie P-A (2011b) Changes in the African monsoon region at medium-term time horizon using 12 AR4 coupled models under the A1b emissions scenario. Atmospheric Science Letters 12:83-88. doi:10.1002/asl.321

Gaetani M, Fontaine B, Roucou P, Baldi M (2010) Influence of the Mediterranean Sea on the West African monsoon: Intraseasonal variability in numerical simulations. J Geophys Res 115:D24115. doi:10.1029/2010jd014436

Gaetani M, Mohino E (2013) Decadal prediction of the Sahelian precipitation in CMIP5 simulations. Journal of Climate 26:7708-7719

Giannini A (2010) Mechanisms of Climate Change in the Semiarid African Sahel: The Local View. Journal of Climate 23:743-756. doi:10.1175/2009jcli3123.1

Grist JP, Nicholson SE (2001) A study of the dynamic factors influencing the rainfall variability in the West African Sahel. Journal of Climate 14:1337-1359

Guan K, Sultan B, Biasutti M, Baron C, Lobell DB (2015) What aspects of future rainfall changes matter for crop yields in West Africa? Geophysical Research Letters 42. doi:10.1002/2015g1063877

Haarsma RJ, Selten FM, Weber SL, Kliphuis M (2005) Sahel rainfall variability and response to greenhouse warming. Geophys Res Lett 32:L17702. doi:10.1029/2005g1023232 
Hoerling M, Hurrell J, Eischeid J, Phillips A (2006) Detection and Attribution of Twentieth-Century Northern and Southern African Rainfall Change. Journal of Climate 19:3989-4008. doi:10.1175/jcli3842.1

Jain AK, Murty MN, Flynn PJ (1999) Data clustering: a review. ACM computing surveys (CSUR) 31:264-323

James R, Washington R (2013) Changes in African temperature and precipitation associated with degrees of global warming. Climatic Change 117:859-872

James R, Washington R, Jones R (2015) Process-based assessment of an ensemble of climate projections for West Africa. Journal of Geophysical Research: Atmospheres 120. doi:10.1002/2014JD022513

Kitoh A, Endo H, Krishna Kumar K, Cavalcanti IFA, Goswami P, Zhou T (2013) Monsoons in a changing world: A regional perspective in a global context. Journal of Geophysical Research: Atmospheres 118:3053-3065. doi:10.1002/jgrd.50258

Knight JR, Folland CK, Scaife AA (2006) Climate impacts of the Atlantic Multidecadal Oscillation. Geophys Res Lett 33:L17706. doi:10.1029/2006g1026242

Knutti R, Furrer R, Tebaldi C, Cermak J, Meehl GA (2010) Challenges in combining projections from multiple climate models. Journal of Climate 23:2739-2758. doi:http://dx.doi.org/10.1175/2009JCLI3361.1

Knutti R, Masson D, Gettelman A (2013) Climate model genealogy: Generation CMIP5 and how we got there. Geophysical Research Letters 40:1194-1199

Koster RD et al. (2004) Regions of strong coupling between soil moisture and precipitation. Science 305:1138-1140

Lebel T, Ali A (2009) Recent trends in the Central and Western Sahel rainfall regime (1990-2007). Journal of Hydrology 375:52-64. doi:10.1016/j.jhydrol.2008.11.030

Lee J-Y, Wang B (2014) Future change of global monsoon in the CMIP5. Climate Dynamics 42:101-119. doi:10.1007/s00382-012-1564-0

L'Hote Y, Mahe G, Some B (2003) The 1990s rainfall in the Sahel: the third driest decade since the beginning of the century. Hydrological Sciences Journal 48:493-496

L'Hote Y, Mahé G, Somé B, Triboulet JP (2002) Analysis of a Sahelian annual rainfall index from 1896 to 2000 ; the drought continues. Hydrological Sciences Journal 47:563-572

Li F, Collins WD, Wehner MF, Williamson DL, Olson JG (2011) Response of precipitation extremes to idealized global warming in an aqua- planet climate model: towards a robust projection across different horizontal resolutions. Tellus A 63:876-883

Li F, Rosa D, Collins WD, Wehner MF (2012) "Super-parameterization": A better way to simulate regional extreme precipitation? Journal of Advances in Modeling Earth Systems 4. doi:10.1029/2011ms000106

Li L, Diallo I, Xu C-Y, Stordal F (2015) Hydrological projections under climate change in the near future by RegCM4 in Southern Africa using a large-scale hydrological model. Journal of Hydrology

Martin ER, Thorncroft C, Booth BB (2014) The multidecadal Atlantic SST-Sahel rainfall teleconnection in CMIP5 simulations. Journal of Climate 27:784-806

Masson D, Knutti R (2011) Climate model genealogy. Geophysical Research Letters 38

Maynard KM, Royer JFR, Chauvin FC (2002) Impact of greenhouse warming on the West African summer monsoon. Climate Dynamics 19:499-514. doi:10.1007/s00382-002-0242-z

McSweeney CF, Jones RG, Booth BB (2012) Selecting ensemble members to provide regional climate change information. Journal of Climate 25:7100-7121

McSweeney C, Jones R, Lee R, Rowell D (2015) Selecting CMIP5 GCMs for downscaling over multiple regions. Climate Dynamics 44:3237-3260

Meinshausen M et al. (2011) The RCP greenhouse gas concentrations and their extensions from 1765 to 2300 . Climatic Change 109:213-241. doi:10.1007/s10584-011-0156-Z

Mohino E, Janicot S, Bader J (2011) Sahel rainfall and decadal to multi-decadal sea surface temperature variability. Climate Dynamics 37:419-440

Monerie P-A, Fontaine B, Roucou P (2012) Expected future changes in the African monsoon between 2030 and 2070 using some CMIP3 and CMIP5 models under a medium-low RCP scenario. Journal of Geophysical Research: Atmospheres (1984-2012) 117:D16111. doi:10.1029/2012JD017510

Monerie P-A, Roucou P, Fontaine B (2013) Mid-century effects of Climate Change on African monsoon dynamics using the A1B emission scenario. International Journal of Climatology 33:881-896. doi:10.1002/joc.3476

Monerie P-A, Biasutti M, Roucou P (2016) On the projected increase of Sahel rainfall during the late rainy season. International Journal of Climatology. doi:10.1002/joc.4638

Nicholson SE (2005) On the question of the "recovery" of the rains in the West African Sahel. Journal of Arid Environments 63:615-641. doi:10.1016/j.jaridenv.2005.03.004

Nicholson SE (2008) The intensity, location and structure of the tropical rainbelt over west Africa as factors in interannual variability. International Journal of Climatology 28:1775-1785

Nicholson SE, Dezfuli AK, Klotter D (2012a) A two-century precipitation dataset for the continent of Africa. Bulletin of the American Meteorological Society 93:1219-1231 
Nicholson SE, Klotter D, Dezfuli AK (2012b) Spatial reconstruction of semi-quantitative precipitation fields over Africa during the nineteenth century from documentary evidence and gauge data. Quaternary Research 78:1323

Nicholson SE (2013) The West African Sahel: A review of recent studies on the rainfall regime and its interannual variability. ISRN Meteorology 2013

Okumura YM, Ohba M, Deser C, Ueda H (2011) A proposed mechanism for the asymmetric duration of El Niño and La Niña. Journal of Climate 24:3822-3829

Ozer P, Erpicum M, DemarÉE G, Vandiepenbeeck M (2003) The Sahelian drought may have ended during the 1990s. Hydrological Sciences Journal 48:489-492. doi:10.1623/hysj.48.3.489.45285

Park J-Y, Bader J, Matei D (2015) Northern-hemispheric differential warming is the key to understanding the discrepancies in the projected Sahel rainfall. Nat Commun 6. doi:10.1038/ncomms6985

Patricola CM, Cook KH (2008) Atmosphere/vegetation feedbacks: A mechanism for abrupt climate change over northern Africa. Journal of Geophysical Research: Atmospheres 113. doi:10.1029/2007jd009608

Pennell C, Reichler T (2011) On the effective number of climate models. Journal of Climate 24:2358-2367. doi:http://dx.doi.org/10.1175/2010JCLI3814.1

Polo I, Ullmann A, Roucou P, Fontaine B (2011) Weather regimes in the Euro-Atlantic and Mediterranean sector, and relationship with West African rainfall over the 1989-2008 period from a self-organizing maps approach. Journal of Climate 24:3423-3432

Richter I, Xie S-P (2008) On the origin of equatorial Atlantic biases in coupled general circulation models. Climate Dynamics 31:587-598. doi:10.1007/s00382-008-0364-z

Richter I, Xie S-P, Wittenberg AT, Masumoto Y (2012) Tropical Atlantic biases and their relation to surface wind stress and terrestrial precipitation. Climate Dynamics 38:985-1001

Roehrig R, Bouniol D, Guichard F, Hourdin F, Redelsperger JL (2013) The present and future of the West African monsoon: a process-oriented assessment of CMIP5 simulations along the AMMA transect. Journal of Climate, 26(17), 6471-6505.

Rowell DP (2003) The Impact of Mediterranean SSTs on the Sahelian Rainfall Season. Journal of Climate 16:849-862. doi:10.1175/1520-0442(2003)016<0849:tiomso>2.0.co;2

Saini R, Wang G, Yu M, Kim J (2015) Comparison of RCM and GCM projections of boreal summer precipitation over Africa. Journal of Geophysical Research: Atmospheres 120:3679-3699. doi:10.1002/2014jd022599

Sanogo S, Fink AH, Omotosho JA, Ba A, Redl R, Ermert V (2015) Spatio-temporal characteristics of the recent rainfall recovery in West Africa. International Journal of Climatology. doi:10.1002/joc.4309

Santer BD et al. (2009) Incorporating model quality information in climate change detection and attribution studies. Proceedings of the National Academy of Sciences 106:14778-14783. doi:citeulike-article-id:5778152

Seth A, Rauscher SA, Biasutti M, Giannini A, Camargo SJ, Rojas M (2013) CMIP5 projected changes in the annual cycle of precipitation in monsoon regions. Journal of Climate 26:7328-7351. doi:http://dx.doi.org/10.1175/JCLI-D-12-00726.1

Skinner CB, Ashfaq M, Diffenbaugh NS (2012) Influence of twenty-first-century atmospheric and sea surface temperature forcing on West African climate. Journal of Climate 25:527-542

Solomon S (2007) Climate change 2007-the physical science basis: Working group I contribution to the fourth assessment report of the IPCC vol 4. Cambridge University Press,

Sultan B et al. (2014) Robust features of future climate change impacts on sorghum yields in West Africa. Environmental Research Letters 9:104006

Sylla MB, Giorgi F, Pal JS, Gibba P, Kebe I, Nikiema M (2015) Projected Changes in the Annual Cycle of High Intensity Precipitation Events over West Africa for the Late 21st Century. Journal of Climate

Taylor KE, Stouffer RJ, Meehl GA (2012) An overview of CMIP5 and the experiment design. Bulletin of the American Meteorological Society 93:485-498. doi:http://dx.doi.org/10.1175/BAMS-D-11-00094.1

Thorncroft C, Blackburn M (1999) Maintenance of the African easterly jet. Quarterly Journal of the Royal Meteorological Society 125:763-786

Ting M, Kushnir Y, Seager R, Li C (2009) Forced and internal twentieth-century sst trends in the north atlantic*. Journal of Climate 22:1469-1481

Uppala SM et al. (2005) The ERA-40 re-analysis. Quarterly Journal of the Royal Meteorological Society 131:29613012

Uppala S, Dee D, Kobayashi S, Berrisford P, Simmons A (2008) Towards a climate data assimilation system: status update of ERA-Interim. ECMWF newsletter 115:12-18

Vizy EK, Cook KH (2012) Mid-Twenty-First-Century Changes in Extreme Events over Northern and Tropical Africa. Journal of Climate 25:5748-5767. doi:10.1175/jcli-d-11-00693.1

Wang G, Alo CA (2012) Changes in precipitation seasonality in West Africa predicted by RegCM3 and the impact of dynamic vegetation feedback. International Journal of Geophysics 2012. doi:10.1155/2012/597205

Ward Jr JH (1963) Hierarchical grouping to optimize an objective function. Journal of the American statistical association 58:236-244 
997 Wehner MF, Smith RL, Bala G, Duffy P (2010) The effect of horizontal resolution on simulation of very extreme US 998 precipitation events in a global atmosphere model. Climate Dynamics 34:241-247

999 Xue Y, Boone A, Taylor CM (2012) Review of Recent Developments and the Future Prospective in West African 1000 


\section{Mean change}

\section{GR1}

GR2

GR3

GR4

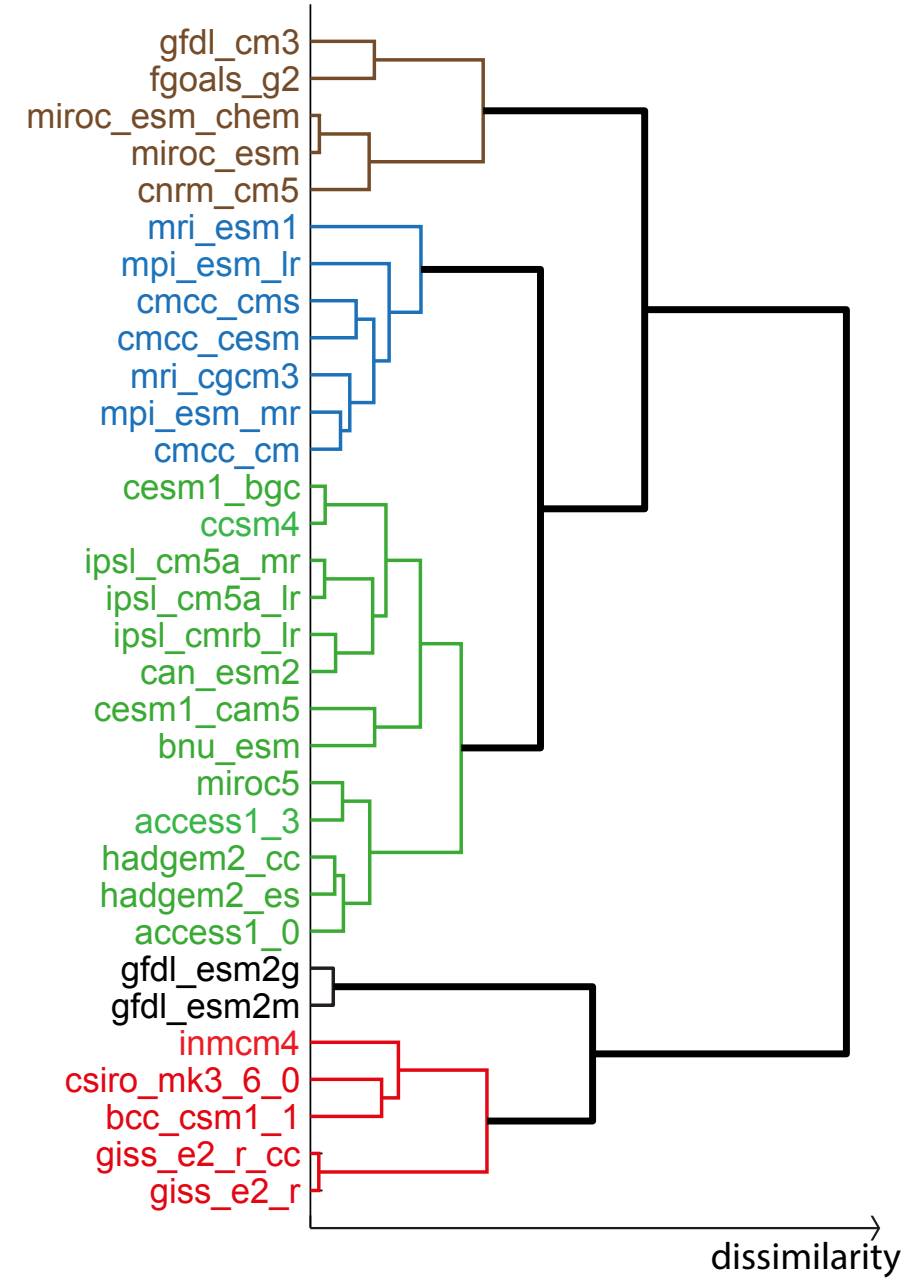


Figure3 $\quad$ tas and ps change GR1
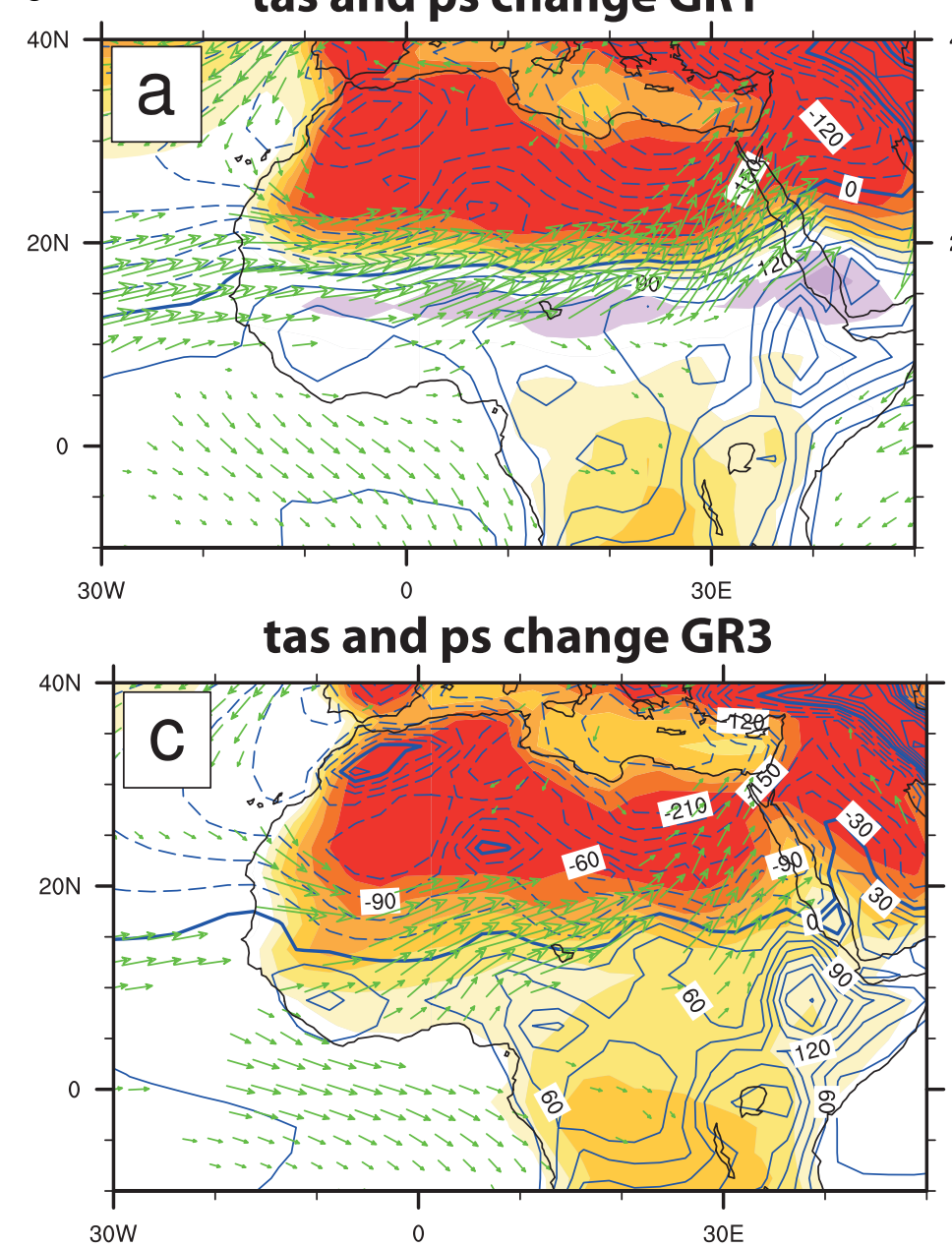

$30 \mathrm{~W}$

\section{tas and ps change GR2}

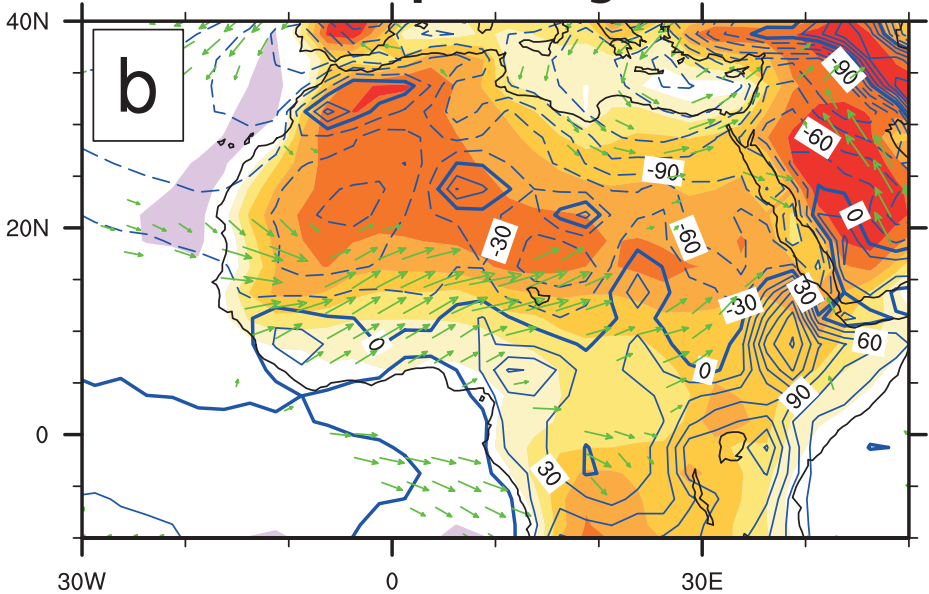

tas and ps change GR4

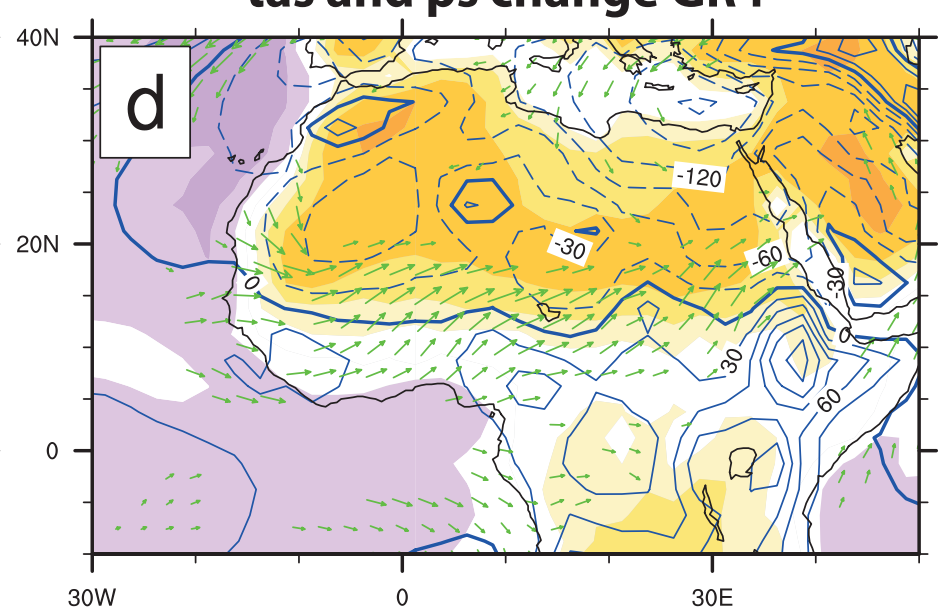

2

$\begin{array}{llllllllllllll}0 & 0.5 & 1 & 1.5 & 2 & 2.5 & 3 & 3.5 & 4 & 4.5 & 5 & 5.5 & 6 & \text { Reference Vector }\end{array}$

zonal wind change GR1

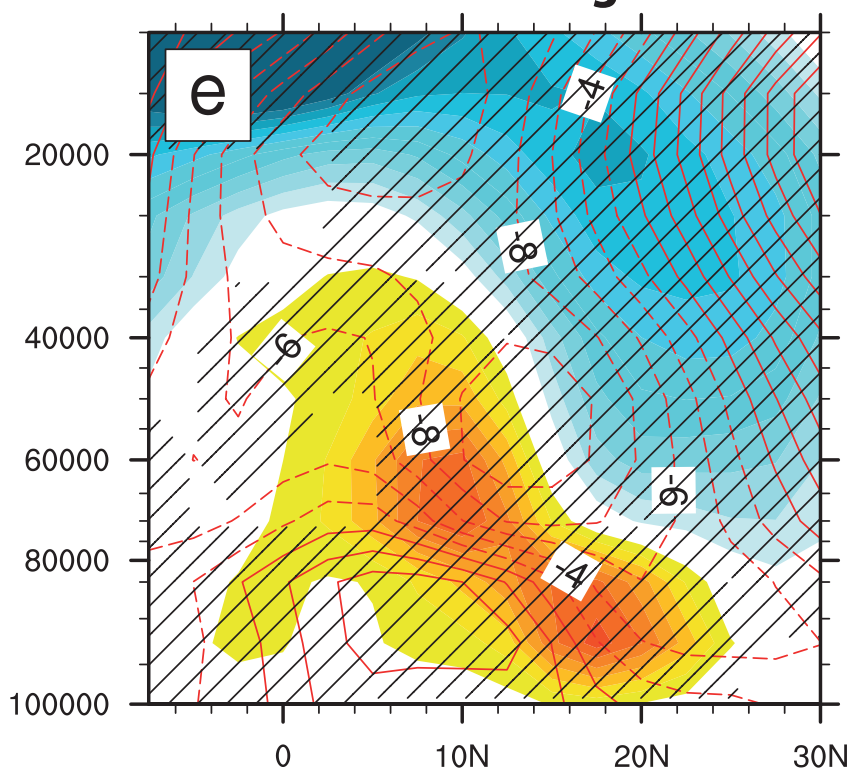

zonal wind change GR3

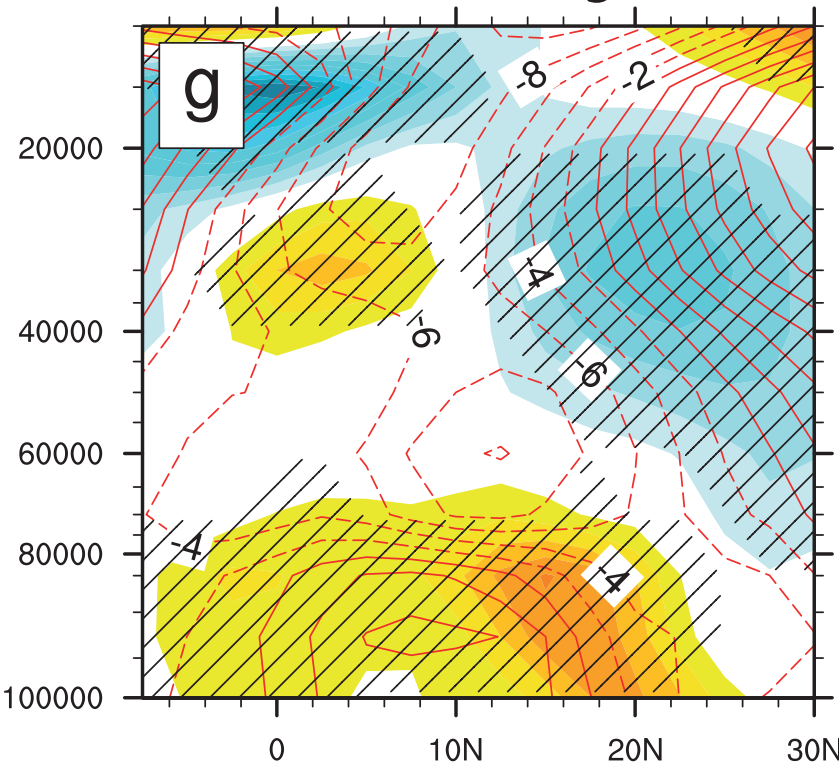

zonal wind change GR2

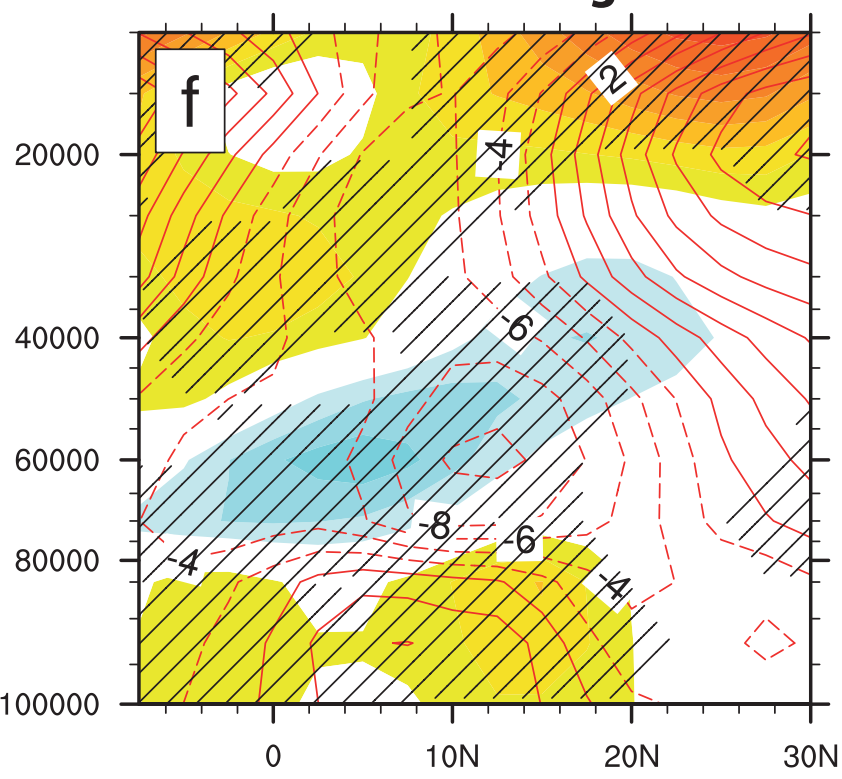

zonal wind change GR4

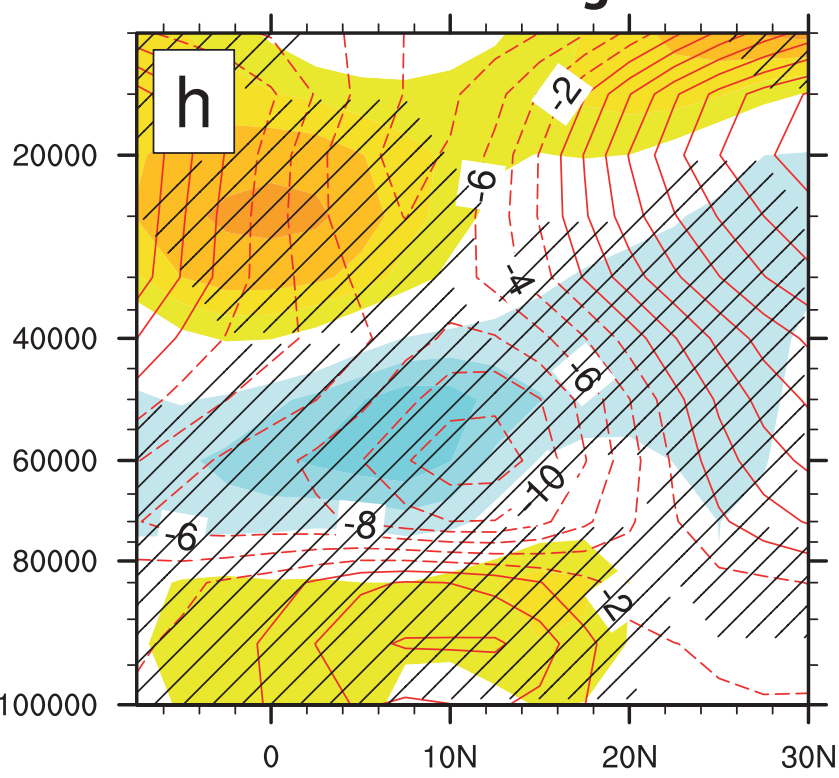


Figure4

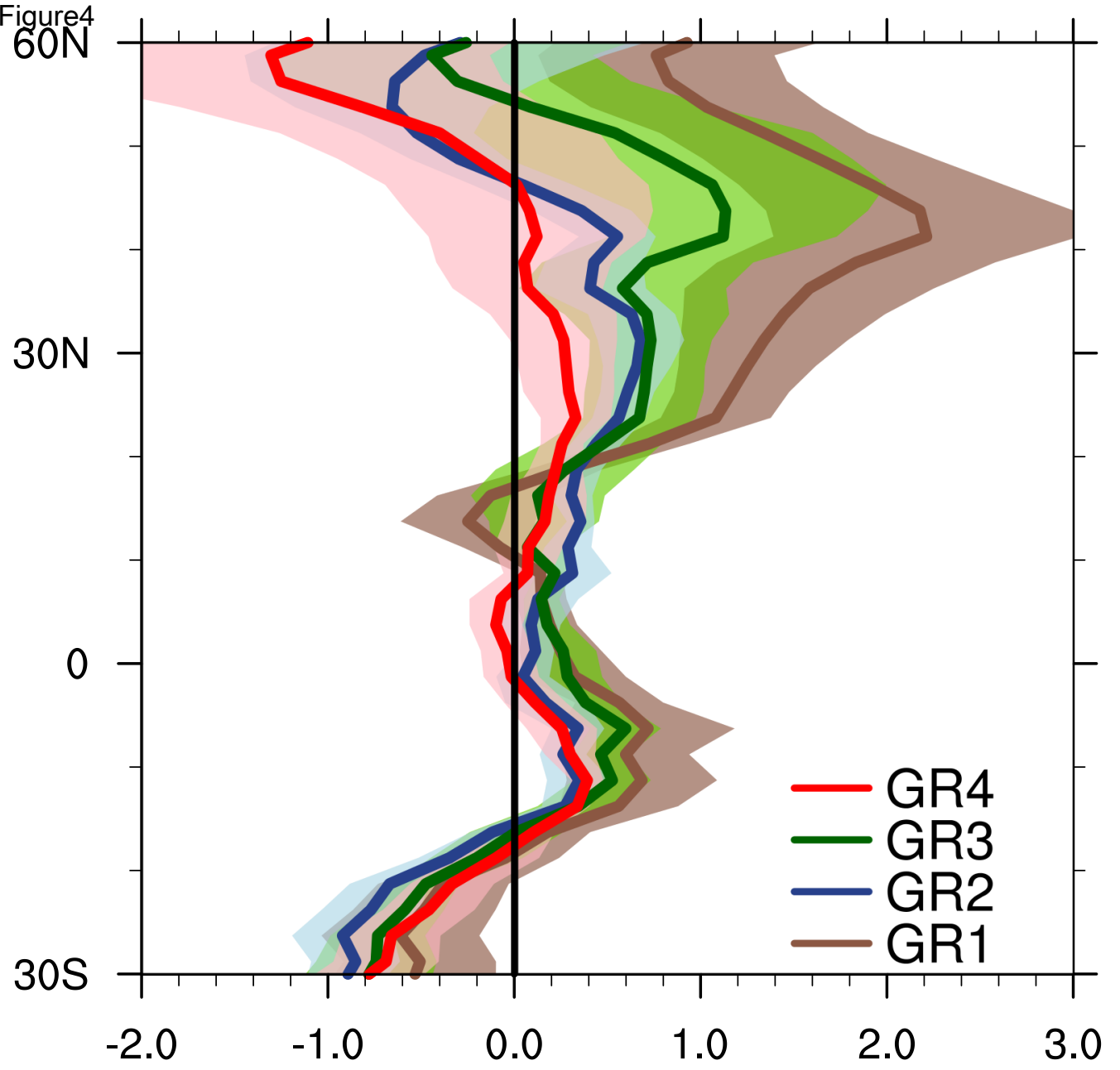




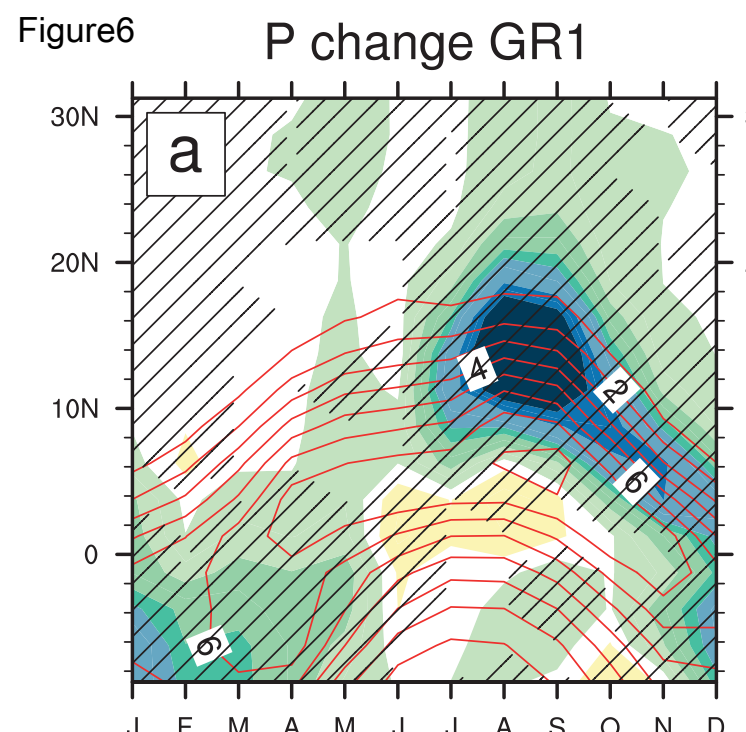

P-E change GR1

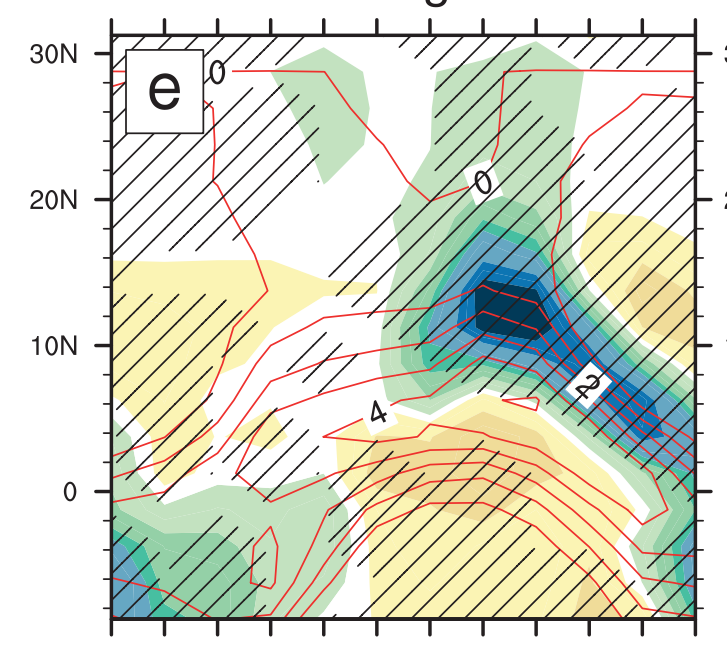

ua@600 hPa change GR1

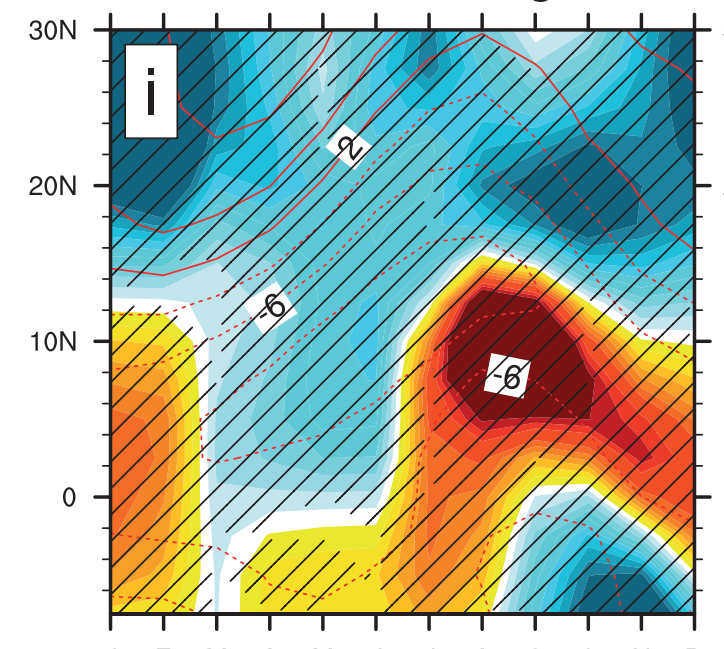

P change GR2

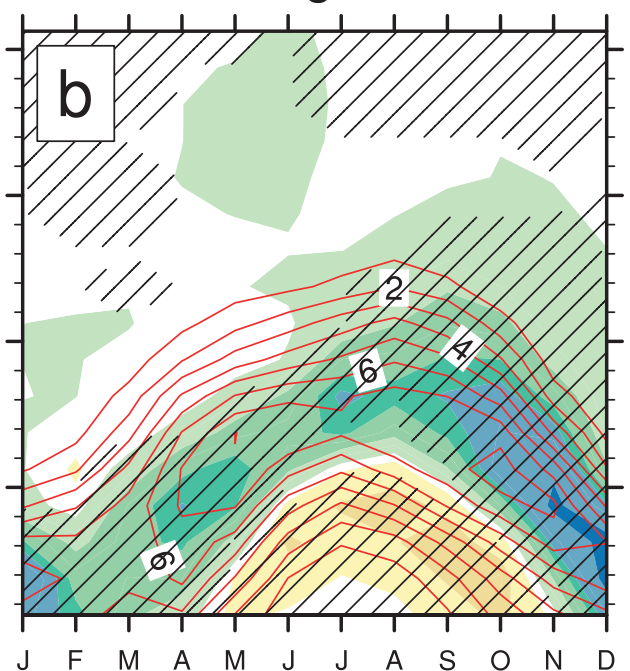

P-E change GR2

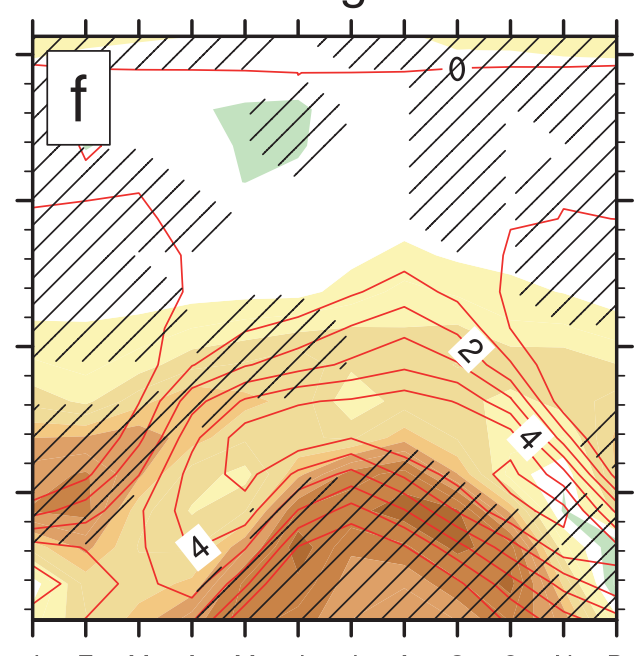

P change GR3

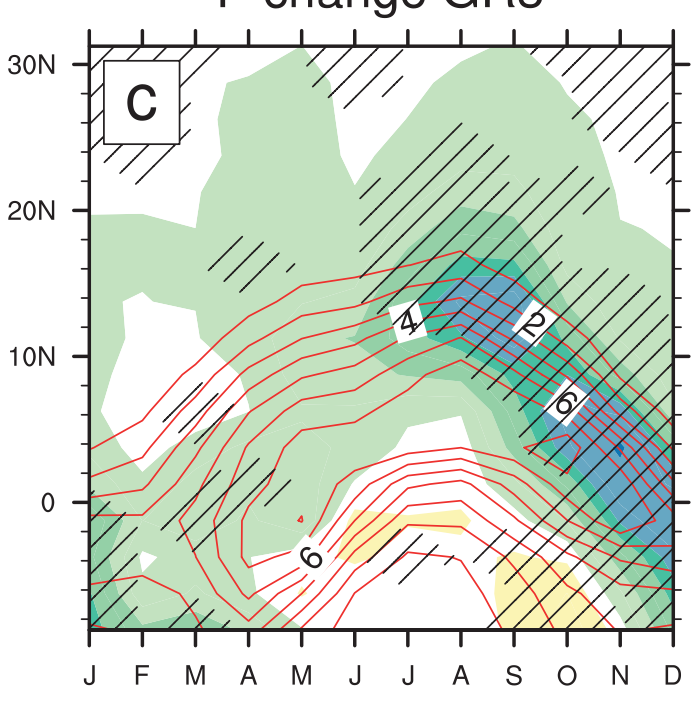

$\mathrm{P}-\mathrm{E}$ change GR3
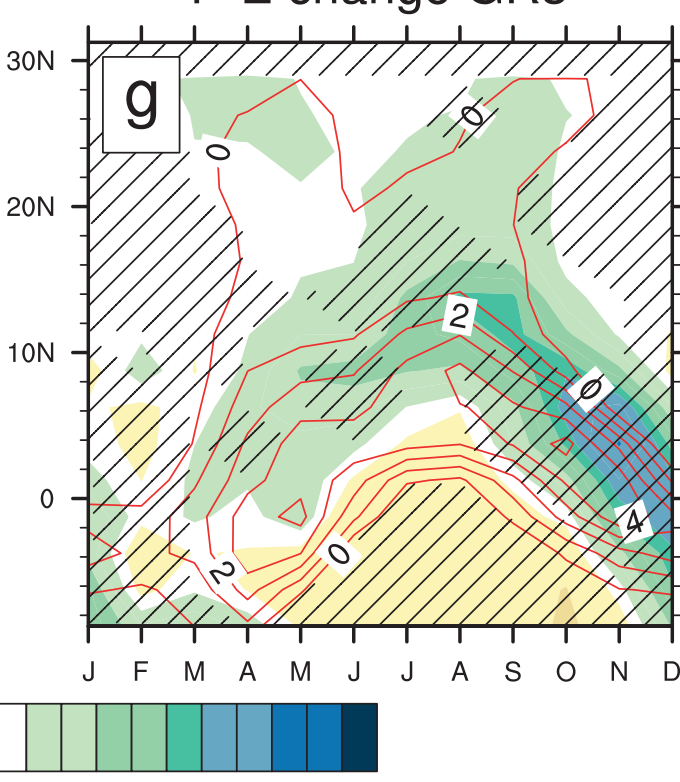

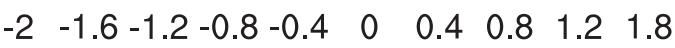

ua@600 hPa change GR2

ua@600hPa change GR3

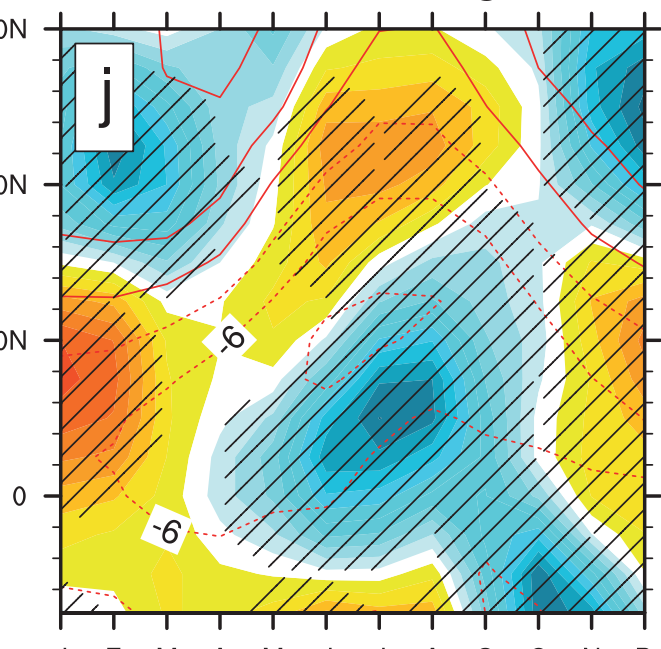

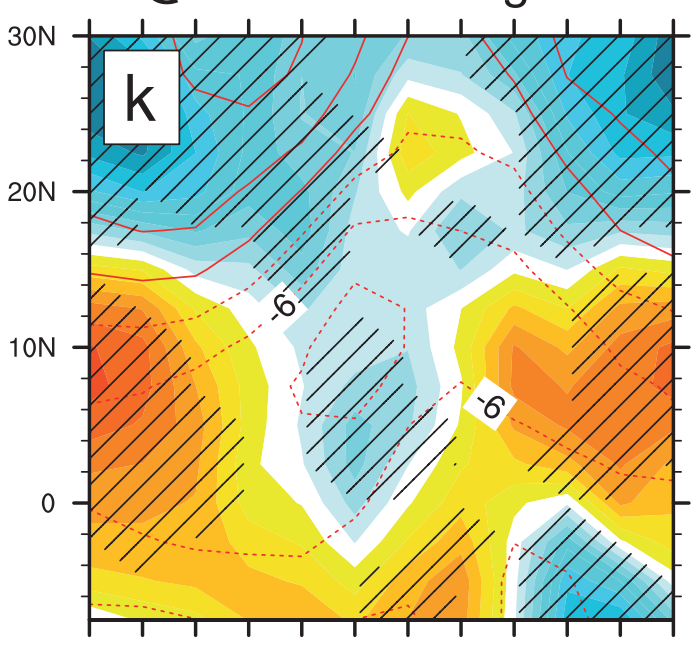

ua@600 hPa change GR4

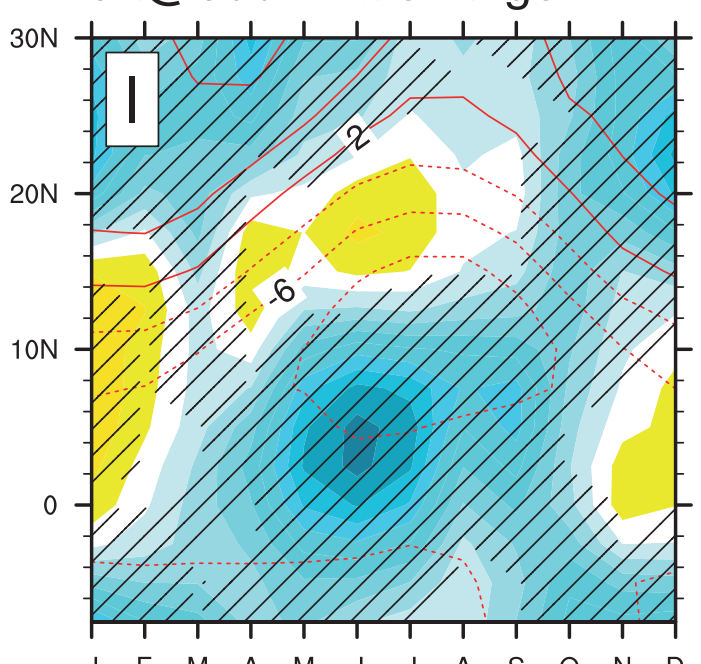

$\begin{array}{lllllllllll}-2 & -1.6 & -1.2 & -0.8 & -0.4 & 0 & 0.4 & 0.8 & 1.2 & 1.8\end{array}$

omega@400 hPa change GR1 omega@400 hPa change GR2 omega@400 hPa change GR3 omega@400 hPa change GR4
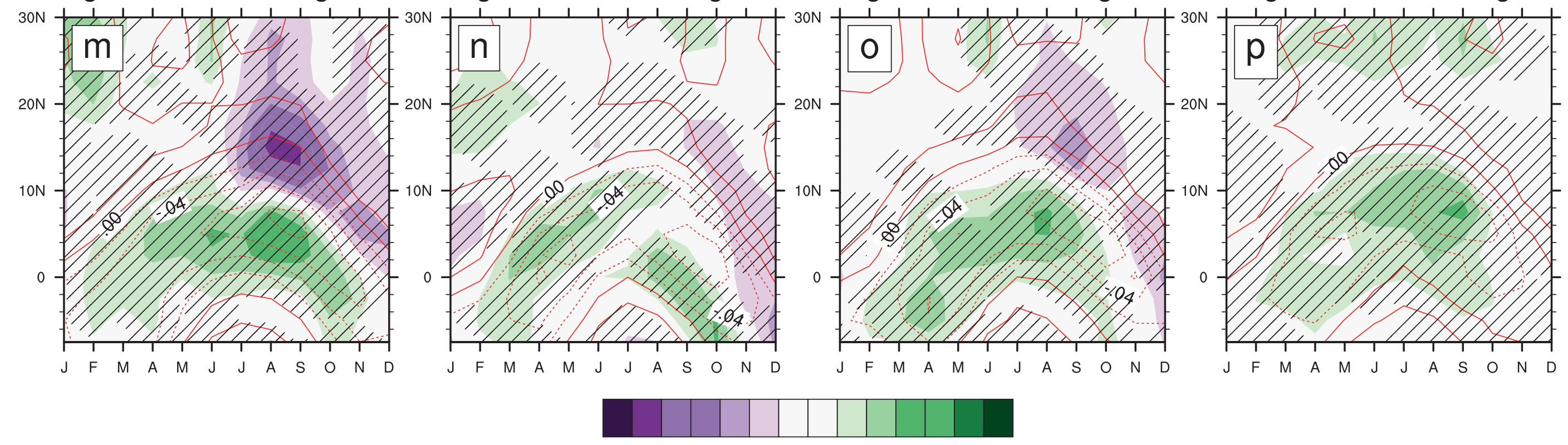
pr, GR1 -GPCP

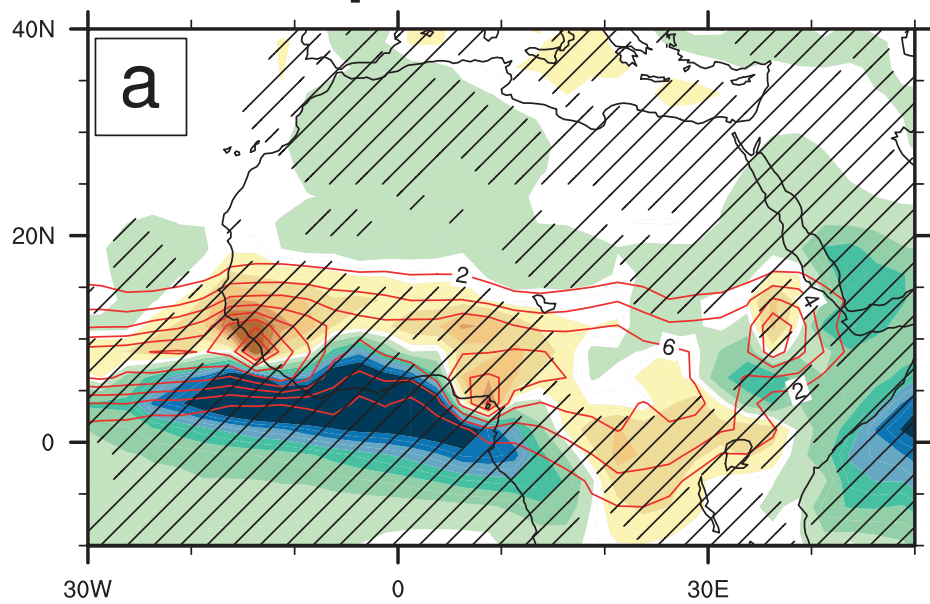

pr, GR3 -GPCP

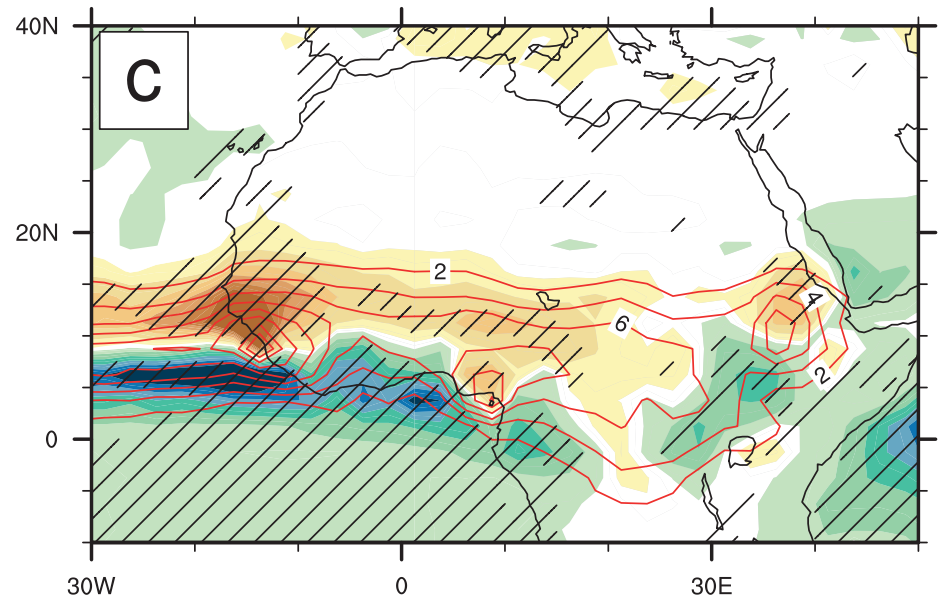

pr, GR2 -GPCP

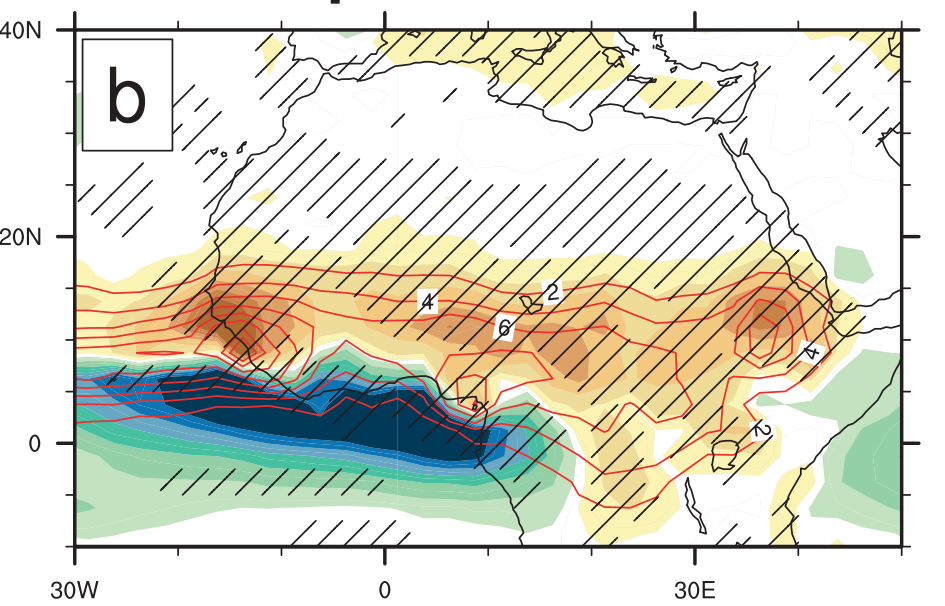

pr, GR4 -GPCP

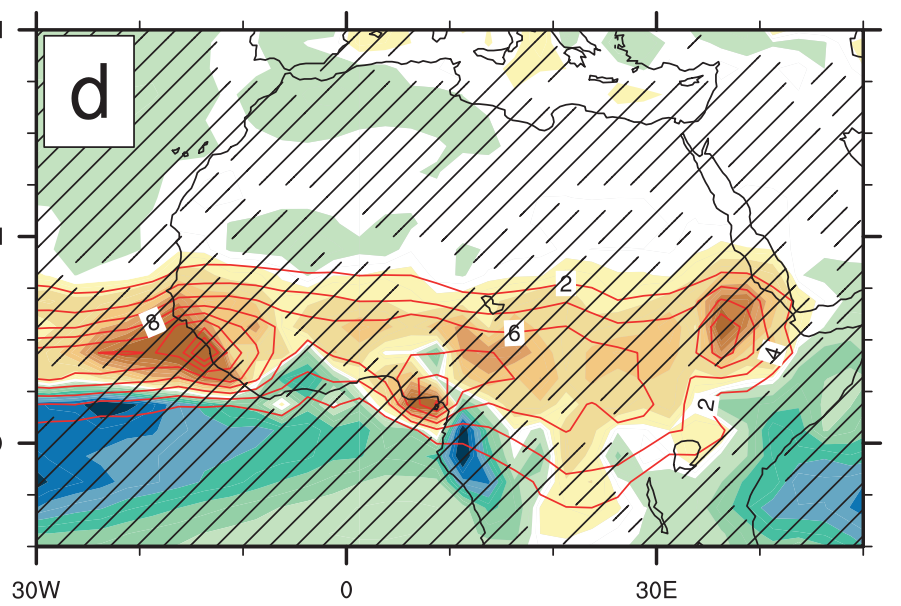

$30 \mathrm{~W}$

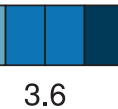

tas, GR1 - era-interim

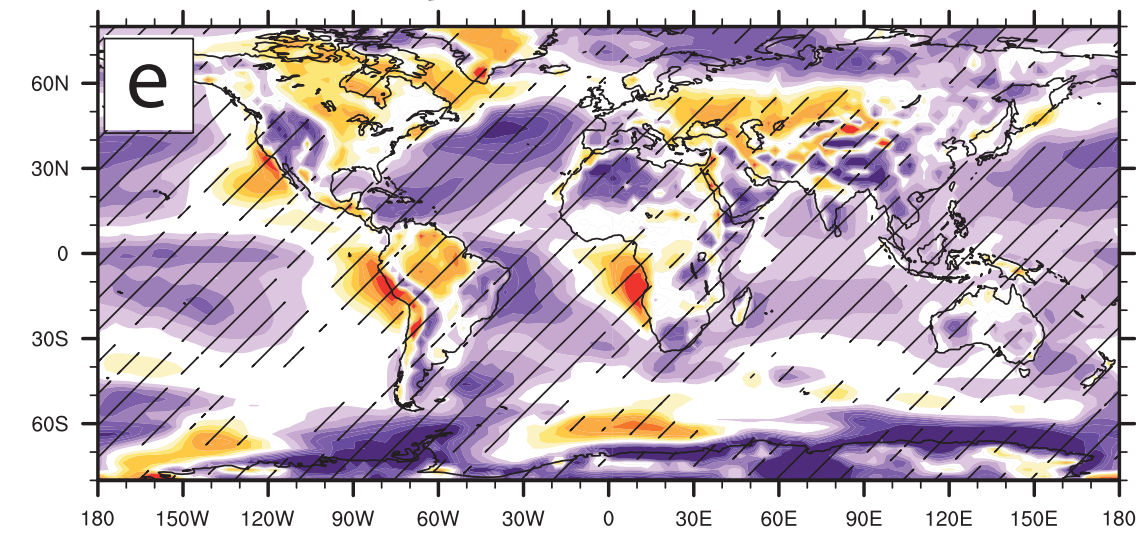

tas, GR3- era-interim

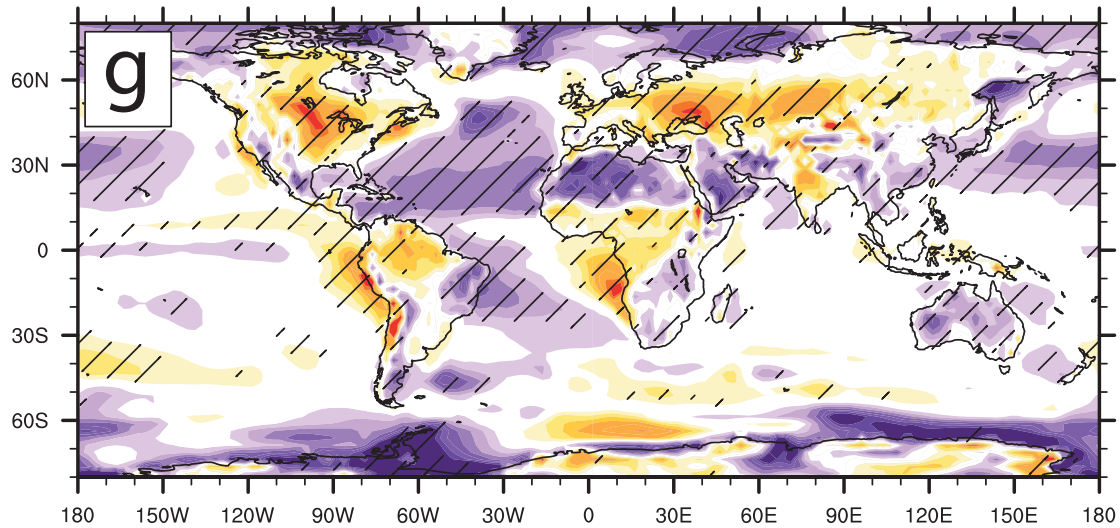

tas, GR2- era-interim

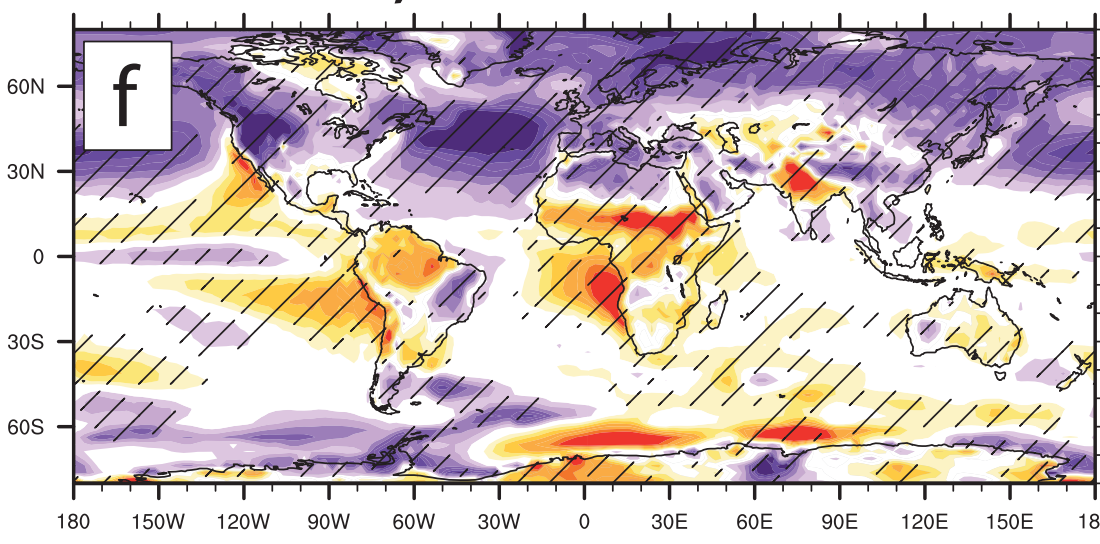

\section{tas, GR4- era-interim}

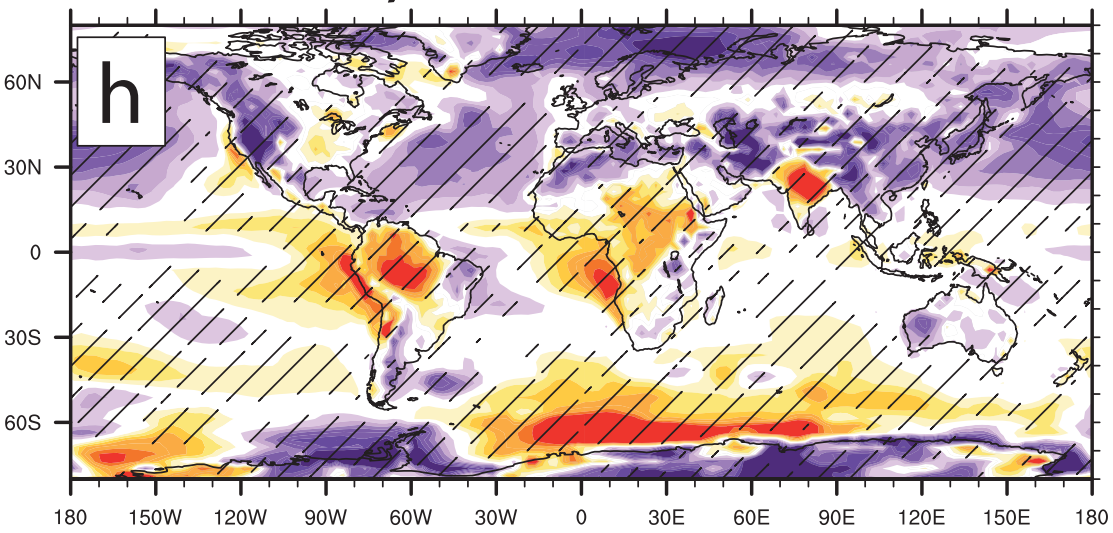




\section{Mean model biases}

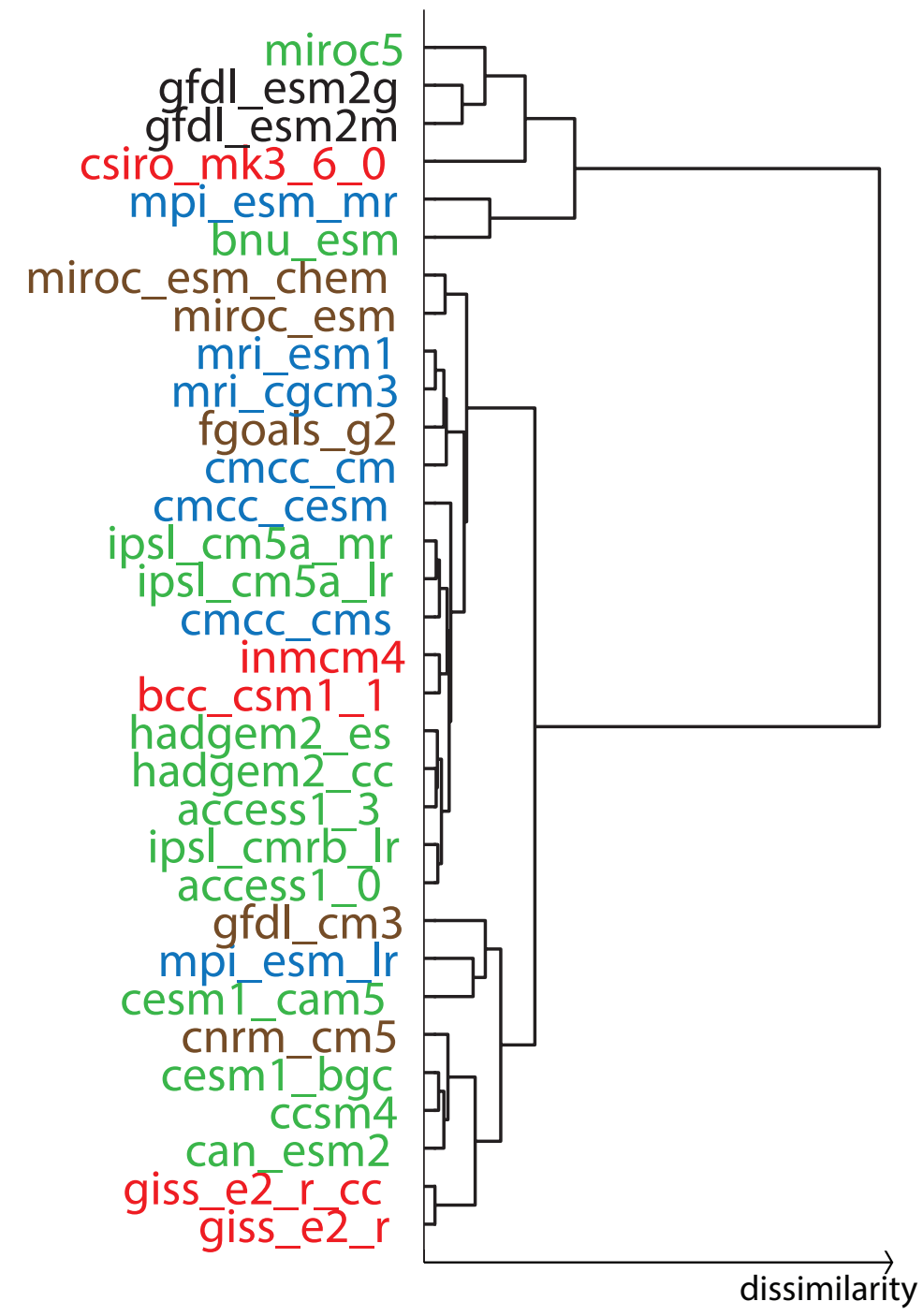




\section{Figure9}

pr, «pattern selection» method, 4 models

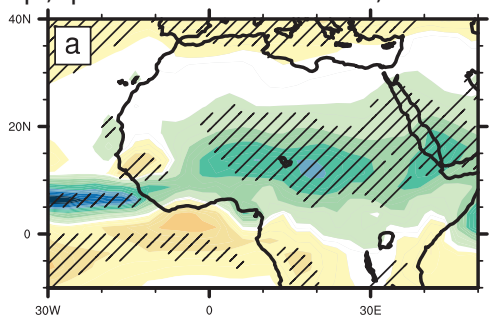

pr, «pattern selection» method, 8 models

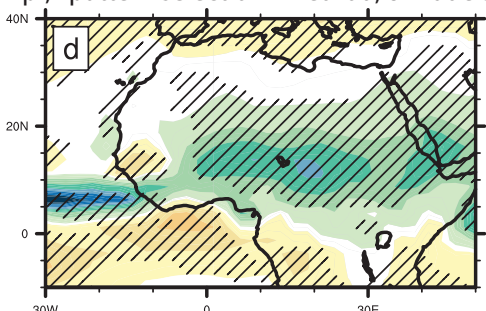

$\mathrm{pr}$, «diversity» method, 4 models

$\mathrm{pr}$, «diversity» method, 8 models

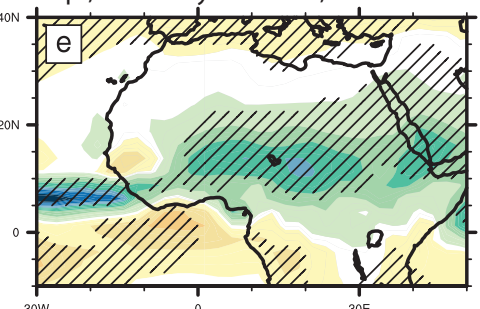

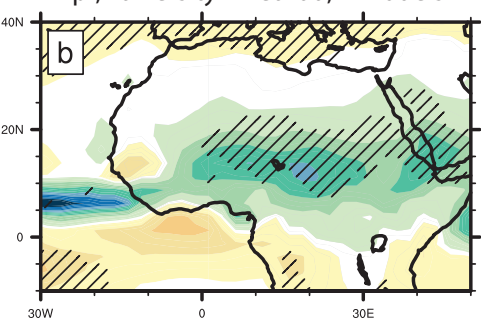

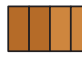

$-1.4-1.1$

spread, «pattern selection» method, 4 models

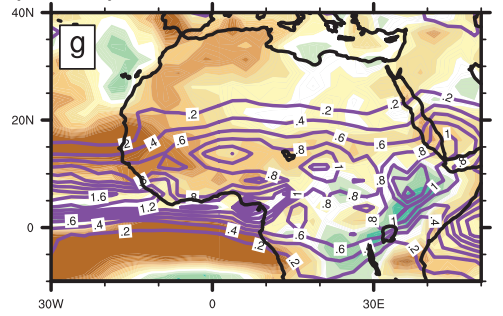

spread, «pattern selection» method, 8 models

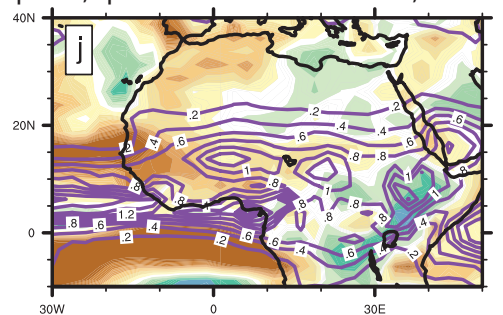

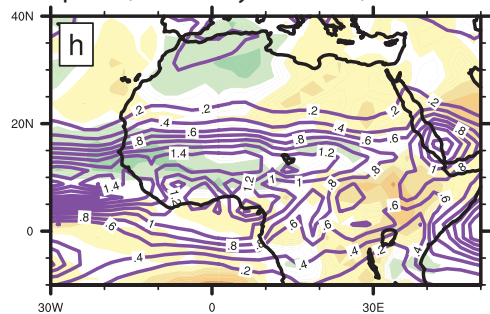

spread, «diversity» method, 8 models

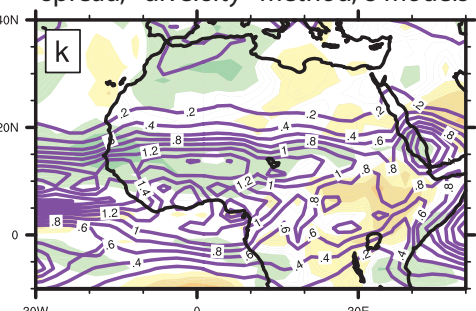

pr, «random» method, 4 models

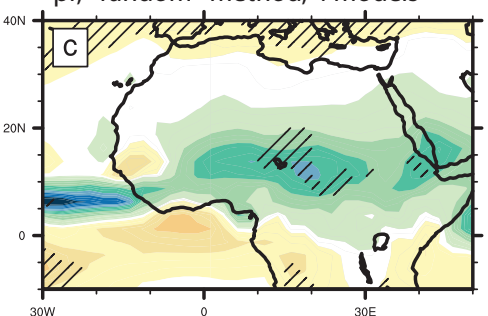

$\mathrm{pr}$, «random» method, 8 models

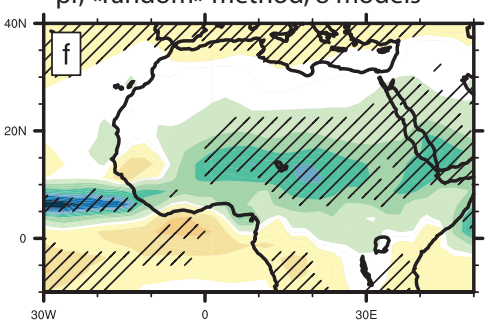

$1.1 \quad 1.4$

spread, «random» method, 4 models

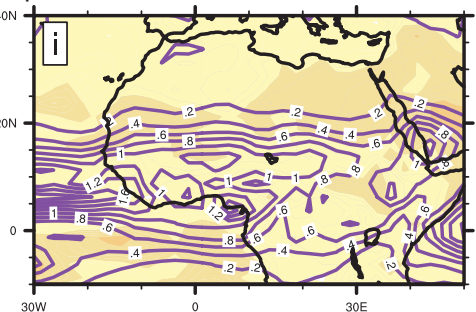

spread, «random» method, 8 models

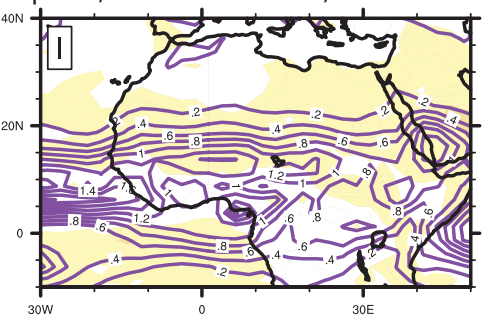


Figure10 Best ensemble of 4 models, pr

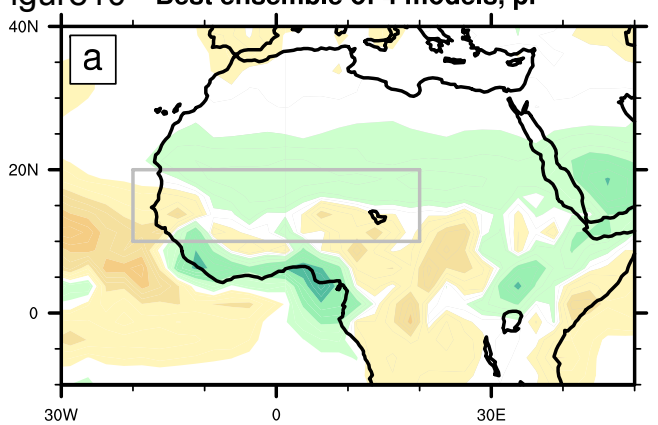

Worst ensemble of 4 models, pr

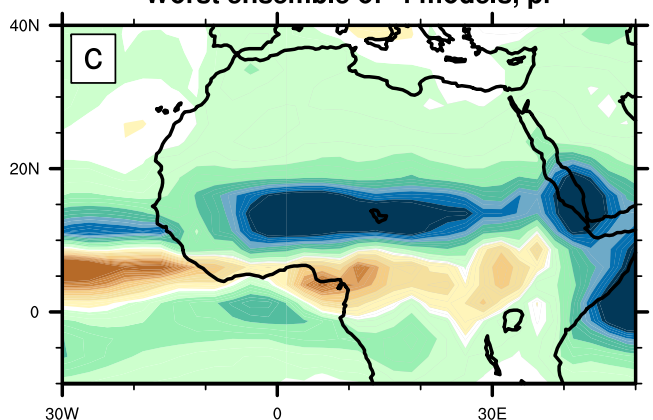

Best ensemble of 4 models, std

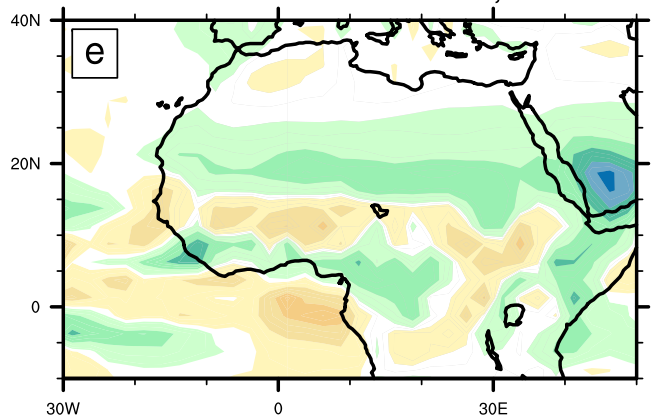

Worst ensemble of 4 models, std

Best ensemble of 8 models, pr

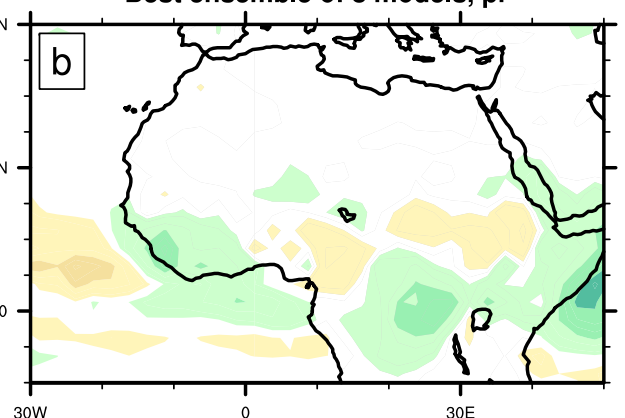

Worst ensemble of 8 models, pr

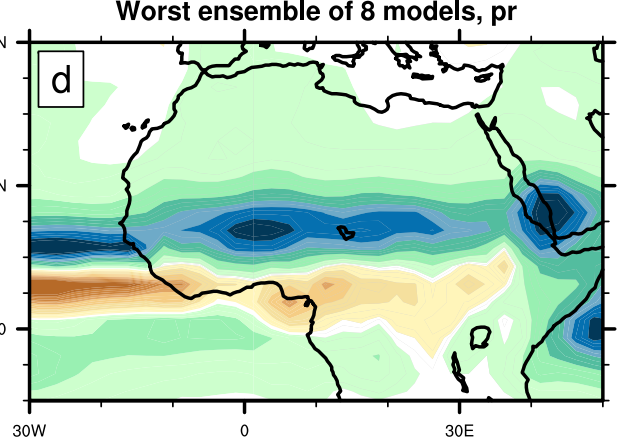

Best ensemble of 8 models, std

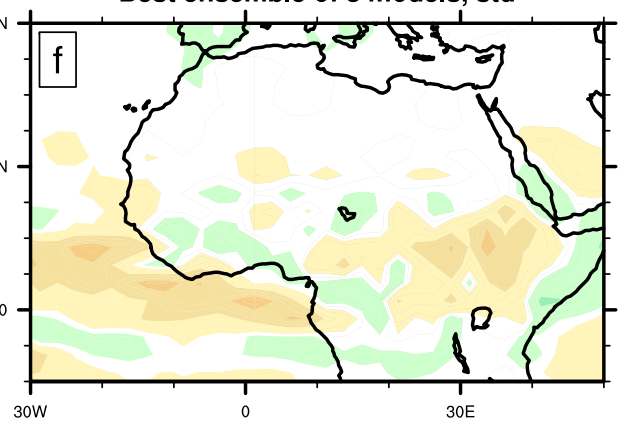

Worst ensemble of 8 models, std
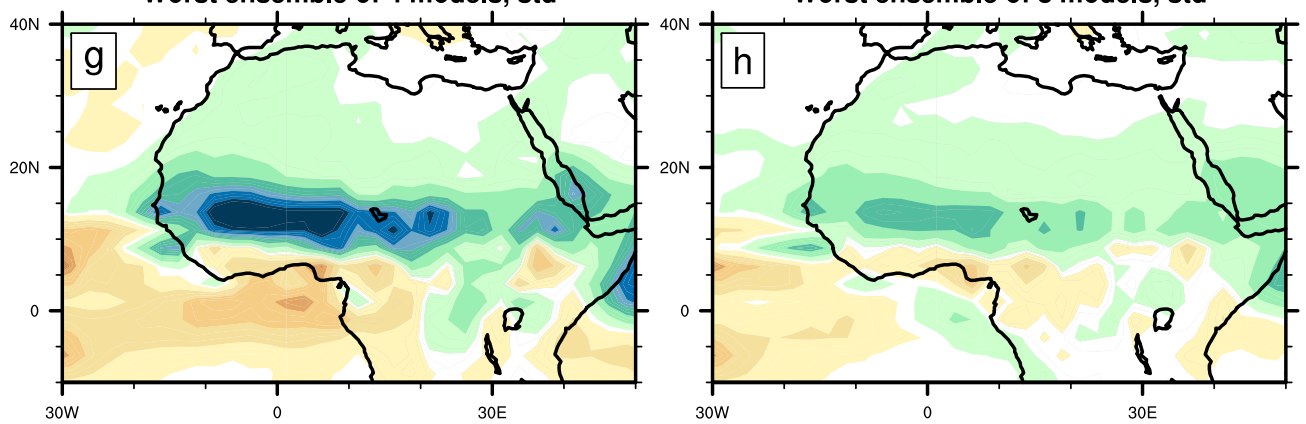

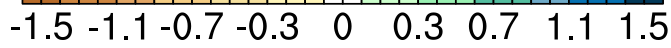


Electronic Supplementary Material

\section{Click here to access/download
Electronic Supplementary Material
Monerie_etal_with_track_changes.doc \\ Click here to access/download
Electronic Supplementary Material
Monerie_etal_with_track_changes.doc \\ Click here to access/download
Electronic Supplementary Material
Monerie_etal_with_track_changes.doc}

